\title{
Dopaminergic Modulation of Cognition in Human Aging
}

\author{
Shu-Chen Li*, Ulman Lindenberger, Lars Nyberg, Hauke R. Heekeren and \\ Lars Bäckman*
}

B rain aging involves neurofunctional, neuroanatomical, and neurochemical changes, and the dynamic interactions between these levels (see Cabeza, Nyberg, and Park, 2005; Lindenberger, Li, and Bäckman, 2006 for recent reviews). There are about 100 billion nerve cells in the human brain and each of these neurons communicates with at least 1,000 other neurons via synaptic mechanisms. Over $99 \%$ of all synapses in the brain use neurochemical transmissions. This chapter addresses age-related neurochemical changes that affect neuronal signal transduction. We focus specifically on age-related impairments in dopamine (DA) systems and their relationships to cognitive deficits later in life. Other neurotransmitter systems-most notably acetylcholine, norepinephrine, serotonin, and glutamate-also undergo alterations during the adult life course (see Morgan and May, 1990; Segovia et al., 2001 for reviews). Thus far, however, the DA systems have attracted the most attention and there is mounting evidence that DA is a key neurotransmitter in the context of cognitive aging. Molecular imaging methods for assessing age-related decline in pre- and post-synaptic markers of the dopaminergic systems, as well as more recent genomic imaging, multimodal imaging, and computational neuroscience approaches to investigate how dopaminergic modulation affects cognitive aging will be particularly highlighted here.

It was only a half century ago that DA was discovered as an independent transmitter in the nervous system, as opposed to a precursor of other transmitters (see Björklund and Dunnett, 2007 for review). The dopaminergic systems have, however, already been widely studied in the context of aging research, owing mainly to (a) the number of well-characterized biomarkers for their pre- and post-synaptic components, (b) the marked age-related decrements observed, and (c) broad involvement of $\mathrm{DA}$ in a wide range of cognitive functions and Parkinson's disease. In the following section, we first describe the major DA systems in the human brain and methods for imaging these systems. Then we review evidence for DA's role in cognition and the relationship between age-related declines in DA systems and cognitive aging. In the last section, we highlight emerging themes and novel approaches that are amenable for investigating dopaminergic modulation in the aging brain and its functionalconsequences. Although this chapter focuses on DA systems, age-related changes in other transmitter systems are likely to also interact with dopaminergic systems to affect cognitive functions. Outstanding issues regarding other transmitter systems that are likely to interact with dopamine in affecting cognitive functions will be discussed as well.

\section{DA Systems in the Human Brain}

Originating in the mid-brain, DA neurons have wide innervations to various subcortical and cortical regions that make up the nigrostriatal, mesocortical, and mesolimbic (see Lewis and Sesack, 1997 for review), as well as the thalamic dopaminergic systems (Sánchez-González et al., 2005; see Figure 5.1 for a schematic diagram of the four pathways). The nigrostriatal and mesolimbic pathways form the two major subcortical DA systems. The cell bodies of the nigrostriatal DA system are located in the substantia nigra in the ventral mesencephalon. The neurons project to the striatum-a region with dense dopaminergic innervations. The mesolimbic DA system originates from a more diffuse collection of neurons in the ventral mesencephalon, medial to the substantia nigra. This region is called the ventral tegmentum. One portion of the neurons here projects to limbic regions such as the nucleus accumbens, the amygdala, the hippocampus, and the anterior cingulate cortex. A third pathway, referred to as the mesocortical DA system, also originates from the ventral tegmentum and projects throughout the neocortex. A fourth pathway that projects to the thalamus, and may be independent from the nigrostriatal and mesolimbic systems, has only recently been identified in the primate brain (Sánchez-González et al., 2005). In line with findings in primates, the thalamus in humans is also innervated by dopamine. For instance, relatively high dopamine D2-receptor binding in the thalamus has been identified in both receptor imaging (e.g., Ito et al., 2008) and in postmortem (Rieck et al., 2004) studies.

\footnotetext{
* Corresponding authors: Shu-Chen Li (shuchenempib-berlin.mpg.de)Lars Bäckman (Lars.Backman.1@ki.se)
} 


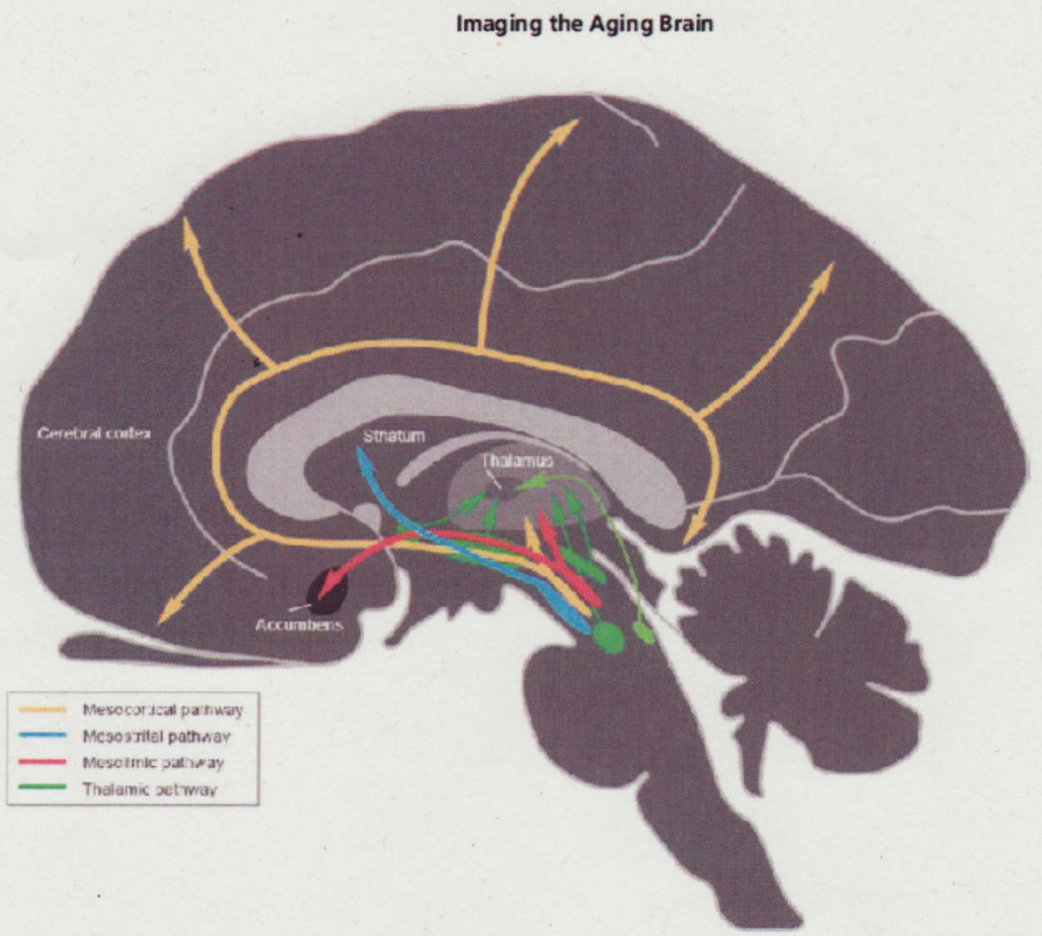

Figure 5-1 A schematic diagram of major dopaminergic pathways in the human brain. (Adapted from Bäckman and Farde, 2005 and Sánchez-González et al., 2005; special thanks to the lab of C. Cavada for providing an earlier draft of the figure.)

\section{Post- and Pre-synaptic Components of DA Systems}

The physiological effects of DA are mediated by binding to any of the five currently identified receptor subtypes (D1-D5). The DA receptor subtypes have distinct anatomical distributions in the brain (Meador-Woodruff, 1994) and can thus be viewed as markers for different clusters of DA-related functions. The five subtypes are grouped into two families on the basis of structural homology and biochemical characteristics. The family of DI-like receptors includes the D1 and D5 subtypes and the family of D2-like receptors including the D2, D3, and D4 subtypes. DA receptors exhibit tissue- and cell-specific expressions that are modulated during development, aging, and in conditions such as Parkinson's disease (Laurier, O'Dowd, and George, 1994; Schambra et al., 1994; Stoessl and de la Fuente-Femandez, 2003). The molecular mechanisms regulating expressions of DA receptors are not well understood, and research in this area is just starting (e.g., Pasuit, Li, and Kuzhikandathil, 2004). The paucity of knowledge makes the task of developing distinct biomarkers for DA receptors difficult and complicates the interpretations of findings. In the following, the two receptor families are referred to as D1 and D2 receptors, as these are the most highly expressed DA receptor subtypes in the human brain. In addition, most of the ligands currently used for receptor imaging do not differentiate among the respective family members.

D1 receptors are more abundant than D2 receptors, reflecting high concentration not only in the striatum but also throughout the neocortex (Hall et al., 1994). D2 receptors are highly concentrated in the striatum. Lower concentrations are expressed in the brain stem and thalamus and concentrations are minute throughout the neocortex (Kessler et al., 1993). Cortically, the D2 receptors have a regional-specific laminar distribution, located in Lamina 2 of the lower temporal cortex and in Lamina 6 of the remaining neocortex (Kohler, Ericson, and Radesater, 1991).

Early work with rodents suggested an anterior-to-posterior gradient of dopaminergic projections to the neocortex, with a preferential DA innervation of the frontal cortex (Ungerstedt, 1971). This generally accepted assumption has, however, not been confirmed by more recent in vitro (Hall et al., 1994; Kessler et al., 1992) and in vivo (Farde et al., 1997) data. Specifically, studies in human subjects demonstrate a homogenous distribution of D1 receptors across the neocortex, and a preferential localization of D2 receptors in the ventral temporal cortex. The species differences in receptor distribution are consistent with findings that dopaminergic terminals are restricted to the frontal lobes in rodents, whereas they are more widely distributed, though with varying degrees of concentrations, across the entire cortex in monkeys and humans (Brown and Goldman, 1977; Gaspar et al., 1989).

Most DA receptors are located on postsynaptic neurons, although a small proportion is expressed on dopamine nerve terminals. The autoreceptors that are presynaptically located on nerve terminals (Carlsson, 1975) regulate dopamine synthesis and release and belong to the family of D2-like receptors (Roth, 1984). DA is synthesized at the presynaptic terminal-a process that is determined by the enzyme tyrosine hydroxylase $(\mathrm{TH})$ that converts tyrosine to the DA precursor, dopa (see Figure 5.2). The DA transporter (DAT) is a membrane-bound protein that serves as a regulator of the synaptic concentration of DA at nerve terminals (Giros et al., 1992). The DAT provides a rapid and efficient 


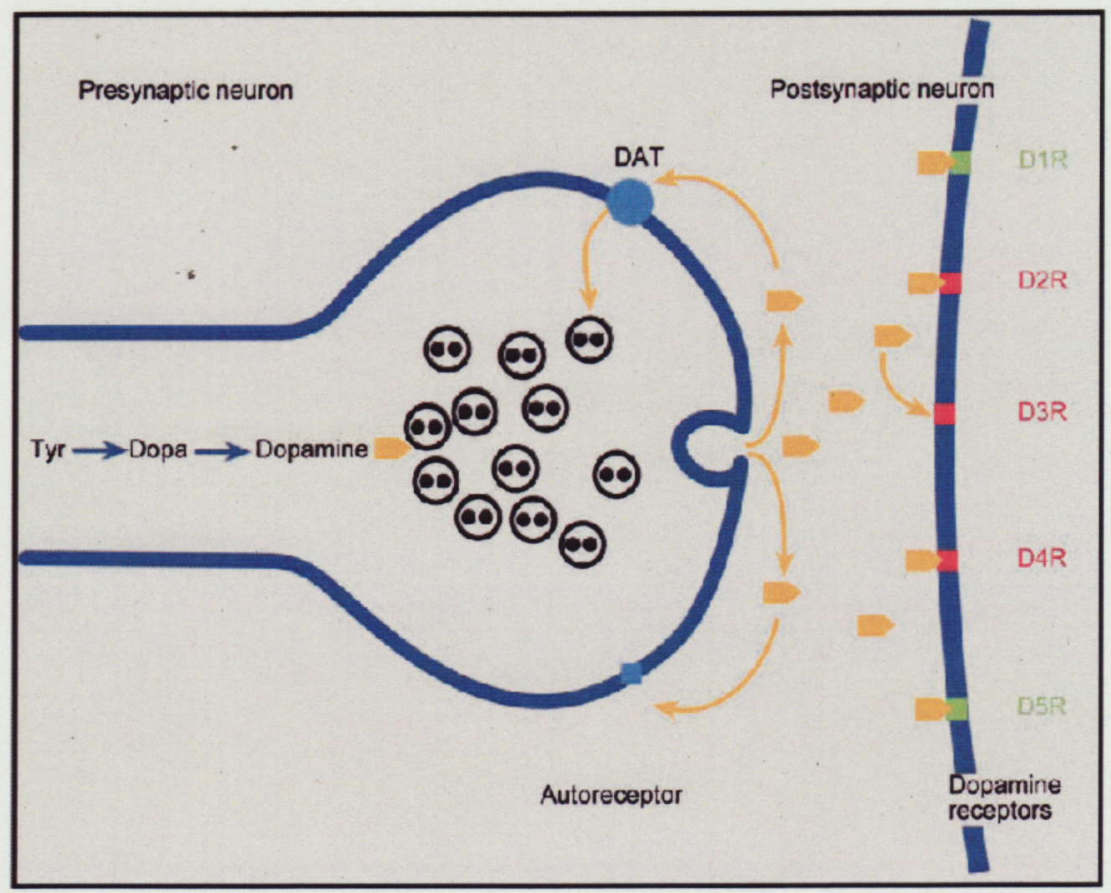

Figure 5-2 A schematic diagram of a DA synapse in the striatum with pre- and postsynaptic components. (Adapted with permission from Bäckman and Farde, 2005; copyright Oxford University Press.)

mechanism for reuptake of synaptic dopamine, and is essential for the regulation of dopamine neurotransmission (Giros et al., 1996). It has been suggested that the concentration of DAT may serve as a marker of the homeostatic tone of the DA system (Jaber et al., 1997; Jones et al., 1998). In addition, it should be noted that a small population of presynaptic D2 receptors also participate in the regulation of DA release (Roth, 1984). The highest concentration of the DAT is found in the striatum, with much lower concentration in the brain stem and the thalamus (Ito et al., 2008). Importantly, DAT is not expressed in the neocortex, where the noradrenaline transporter serves as a regulator of DA concentration. Other than the DAT, which is a DA specific transporter, the vesicular monoamine transporter (VMAT) is another presynaptic protein that transports monoamines, including DA, norepinephrine, and serotonin (Chen et al., 2008; Taylor et al., 2000). The VMAT - specifically the type-2 transporter VMAT2 - transports intracellular monoamines into the synaptic vesicles and is expressed in all monoaminergic neurons. In the striatum, $95 \%$ of the VMAT2 binding takes place in dopaminergic neurons (Taylor et al., 2000). A schematic illustration of the different components of the striatal DA synapse is shown in Figure 5.2.

\section{Imaging Dopaminergic Systems}

The concentration of most receptor proteins in the brain is in the nanomolar range. Such low concentrations cannot be detected using magnetic resonance (MR)-based techniques. The nuclear medicine imaging techniques, positron emission tomography
(PET) and single photon emission tomography (SPECT), are ideal for this purpose, as they have a clear sensitivity advantage over MR-based techniques (Bäckman and Farde, 2005). The PET and SPECT techniques employ radioactive tracers to generate images reflecting the distribution of ligands (i.e., signal triggering molecules that bind to specific target receptors of transmitters) for specific molecules in the brain, and they can be used to study the synthesis and release of neurotransmitters and the availability of receptors (see McGuire et al., 2008 for review). PET detects rather short-lived radionuclides that decay via release of a positron, whereas SPECT detects more long-lived radionuclides that decay by release of a gamma ray.

Various ligands for imaging the different pre- and postsynaptic markers of the dopaminergic systems in the human brain have been developed (see Cropley et al., 2006; Halldin et al., 2001, for overviews). PET studies on biochemical markers for specific neurotransmission systems depend on the availability of suitable ligands that can be rapidly labeled with short-lived radionuclides such as carbon-11, which has a half-life of 20.3 minutes. An advantage of radio-labeling with carbon-11, by substitution of the naturally occurring carbon-12, is that the structure and properties of the molecule remain unchanged. When conducting a PET study, a trace amount of about $1 \mu \mathrm{g}$ of the radioligand is injected intravenously and brain radioactivity is measured continuously for about one hour while the subject lies on a scanner table with the head fixated. The relatively long acquisition time is one reason for the excellent test-retest reproducibility, which is usually within $5 \%$ of discrepancy (Nordström et al., 1992). The binding potential (BP) is a commonly used parameter in PET research on 
neuroreceptor binding. This parameter represents the ratio $\mathrm{Bmax}$ $\mathrm{Kd}$, where $\mathrm{Bmax}$ is the concentration of a protein in a brain region and $\mathrm{Kd}$ is the apparent in vivo affinity of the radioligand for the receptor.

The benzazepine [11C]SCH23390 was the first radioligand developed for PET visualization of the D1 receptor (Farde et al. 1987) and has since been a reference ligand for this purpose. [11C]NNC112 is a more recently developed ligand that provides a higher signal-to-noise ratio for cortical DI receptors (Halldin et al., 1998). The most commonly used radioligand for PET examination of D2 receptors is [1 IC] ]raclopride (Farde et al., 1986). This ligand is suitable for quantification in regions with a high density of D2 receptors (i.e., the striatum). Another radioligand, [1IC]FLB457, has a very high affinity for D2 receptors and is one example of ligands suitable for visualization of low-density D2 populations in the limbic system and the neocortex (Farde et al. 1997). More recently, the BP of [11C]FLB457 in the hippocampus has been found to be positively correlated with measures of episodic memory and executive control in young adults (Takahashi et al., 2006).

The L-[18F]DOPA was the first radiotracer developed for imaging of the presynaptic DA neuron (Garnett et al., 1983). PET studies with $\mathrm{L}-[18 \mathrm{~F}] \mathrm{DOPA}$ provide the rate constant $\mathrm{k} 3$, which is assumed to serve as an index of DA synthesis. The trace $6-[18 \mathrm{~F}]$ fluoro-L-m-tyrosine (FMT) is another marker for quantifying presynaptic DA synthesis (Cools et al., 2008; Eberling et al., 2004; Nahmias et al., 1995). Further, different cocaine analogues have been developed for quantifying DAT BP. Of these, [123I] $\mathrm{B}$-CIT is the most widely used ligand for SPECT imaging of the DAT (Neumeyer et al., 1991). This ligand, however, also has an affinity for serotonin and noradrenaline transporters. Analogues such as [11C]B-CIT-FE (Farde et al., 2000) and [11C] PE2] (Halldin et al., 2003) provide a more selective signal and are currently used in PET studies. In particular, [11C]PE2I is also promising for detailed examination of extrastriatal DAT populations, such as those in the midbrain. Regarding PET imaging of striatal VMAT, [11C]dihydrotetrabenazine (DTBZ) is a commonly used ligand (Frey et al., 1995).

In summary, various ligands have been developed for imaging different components of the dopaminergic systems using PET or SPECT techniques. It is currently possible to use a range of molecular imaging methods to assess striatal or extrastriatal dopamine D1 and D2 receptor binding, DAT binding, and endogenous DA synthesis rate, with some ligands being appropriate for the striatal ([11C]raclopride) and others for the extrastriatal (e.g., [11C]FLB457) components of the DA systems (see Frankle, 2007 for review). Efforts at establishing a normative molecula imaging database of DA systems in healthy individuals are emerging (Ito et al., 2008). With these methodological developments, receptor imaging technologies provide new avenues for understanding the age-related decline in pre- and postsynaptic mechanisms of DA systems and their implications for cognitive deficits in late life.

\section{DA and Cognition}

Data from animal work, clinical and pharmacological research, candidate gene association studies, and computational neuroscience all converge to demonstrate a major influence of dopaminergic modulation on a wide range of cognitive functions. Ample evidence from animal studies shows that lesions on the
DA systems at multiple sites (e.g., prefrontal cortex, nucleus accumbens, subthalamic nucleus) cause impairment in higherorder cognitive functions such as attention, memory, and inhibition (see Bäckman et al., 2006, for review). Clinical studies on patient groups with severe alterations of the DA systems (e.g., Parkinson's disease and Huntington's disease) reveal deficits in several cognitive functions such as executive functioning, episodic memory, and cognitive speed (Brown and Marsden, 1990; Brandt and Butters, 1986). Moreover, PET studies show strong relations between DA biomarkers and cognitive performance assessed outside the scanner in both Parkinson's (Bruck et al., 2005) and Huntington's (Bäckman et al., 1997) patients.

A range of association studies with candidate genes implicating dopaminergic neurotransmission provided further support for the DA-cognition link. For example, the COMT enzyme degrades DA in the prefrontal cortex (Weinshilboum et al., 1999). A common val/met polymorphism accounts for much of the enzymatic activity (val $>$ met), resulting in less DA availability in frontal DI receptors among val carriers (Egan et al., 2001). In executively demanding tasks (e.g., working memory, Wisconsin Card Sorting) an advantage of met carriers has been found (see Goldberg and Weinberger, 2004 for review). Relatedly, variations in the DAT gene (i.e., number of tandem repeats) are associated with DAT availability in the striatum (more repeats $>$ fewer repeats), translating into less synaptic dopamine for persons with more repeats (Maher et al., 2002). Alleles with 9 or 10 repeats are most common (Mitchell et al., 2000). Behavioral evidence shows lower performance among 10-repeat carriers in tasks assessing speed and attention ( $L o o$ et al., 2003) as well as response inhibition (Cornish et al., 2005).

Whereas gene-association studies on the DA-cognition link build on individual differences in genetic predispositions for dopaminergic modulation, pharmacological studies intervene directly with activity in the dopaminergic systems. Pharmacological manipulations of the DA systems (i.e., increased activity through agonists or decreased activity through antagonists) have been shown to affect cognition in humans and animals alike. In general, agonist studies indicate performance benefits in cognitive tasks (e.g., working memory, speed, attention, and reinforcement learning), whereas antagonist studies show decrements in the same task domains (Halliday et al., 1994; Luciana and Collins, 1997; Pizzagalli et al., 2008; Ramaekers et al., 1999; Sawaguchi and Goldman-Rakic, 1991; Servan-Schreiber et al., 1998). However, the effects of these compounds are not entirely consistent. In particular, they tend to vary with dosage and baseline cognitive capacity (Kimberg and DEsposito, 2003; Kimberg, D́Esposito, and Farah, 1997). These findings have been interpreted in terms of an inverted U-shaped function relating DA levels to cognitive performance (Cai and Arnsten, 1997; Cools et al., 2001; Goldman-Rakic, Muly, and Williams, 2000; Knutson and Gibbs, 2007; Li and Sikström, 2002). Evidence in favor of this account was obtained in a study that combined molecular genetics with pharmacology and brain imaging (Mattay et al., 2003). In this study, val carriers of the COMT gene (less frontal DA signaling) had to recruit more frontal tissue than met carriers to achieve the same performance level in a working-memory task, a pattern suggesting lower neural efficiency among val carriers. Under the influence of a DA agonist, however, the pattern was reversed, with the val carriers showing a more efficient frontal response and the met carriers a less efficient response. Obviously, this pattem of data provides direct support for the viability of the inverted $U$-shape account of DA and cognition. 
In addition to these lines of empirical evidence, various computational approaches have been introduced to understand the mechanisms whereby dopaminergic modulation affects cognition (see Rolls et al., 2008 for review). These attempts range from realistic biophysical firing rate models.of how D1 and D2 receptors affect the stability of working memory representations (Durstewitz, Seamans, and Sejnowksi, 2000; see also Seamans and Yang, 2004, for review) to more abstract models of dopaminergic effects on the dynamic connectivity between prefrontal cortex and basal ganglia (O'Reilly and Frank, 2006). Other models focus on DA's general computational role in affecting the signal-to-noise ratio of neuronal signal transduction (Cohen and Servan-Schreiber, 1992; Li, Lindenberger, and Siktröm, 2001) or outcome-based valuation in reinforcement learning (see Montague, Hyman, and Cohen, 2004 for review).

Although the different computational approaches differ in their level of analysis and biophysical specificity, one basic assumption shared by most theories is that dopaminergic modulation influences the properties of neuronal representations of cognitive and perceptual events. For instance, a two-stage model of dopaminergic modulation of working memory aims at capturing the dynamic interactions between $\mathrm{DA}$ and NMDA receptors in affecting the neuronal representations of memory items in the prefrontal cortex (Durstewitz, Seamans, and Sejnowksi, 2000). Specifically, when D2 receptor modulation predominates during the first stage, the prefrontal cortex (PFC)network is supposed to be in an exploratory state with multiple weak representations. However, in a second stage, when D1 receptor modulation predominates, heightened inhibitory mechanisms weed out weaker representations, and enhance the representation of the stronger inputs (Seamans and Yang, 2004; see Figure 5.3a). This effect is nicely paralleled by results from other models that aim at explicating the computational effect of dopaminergic modulation on the signal-to-noise ratio of information processing at a more molar level (Cohen and Servan-Schreiber, 1992; Li, Lindenberger, and Sikström, 2001). As the gain parameter of a neural network's activation function is attenuated or increased to mimic deficient or excessive dopaminergic modulation, respectively, the
Figure 5-3 (a) A two-stage model of dopaminergic modulation of memory representations in the prefrontal cortex. Plotted are simulations of activation in PFC. Peaks denote activated states, corresponding to the sustained recurrent activity required to hold items in working memory. The left panel shows the explor ation state, where D2 modulation predominates, with a net reduction in inhibition resulting in multiple weak representations. The right panel shows the representation sharpening state, where D1 modulation predominates, with a net increase in inhibition resulting strong focused representation. (Adapted with permission from Seamans and Yang, 2004, copyright Elsevier.) Dopamine modulates the signal-to-noise ratio of neural information processing and affects the (b) distinctiveness of memory representations (c) and memory span. Simulating deficient or excessive dopaminergic modulation, by respectively attenuating or increasing the gain parameter (G) of the activation function of a neural network, results in less distinctive internal representations. Less distinctive representations, in turn, result in limited memory spans. (Adapted with permission from Li and Siktröm, 2002; copyright Elsevier.) (a)

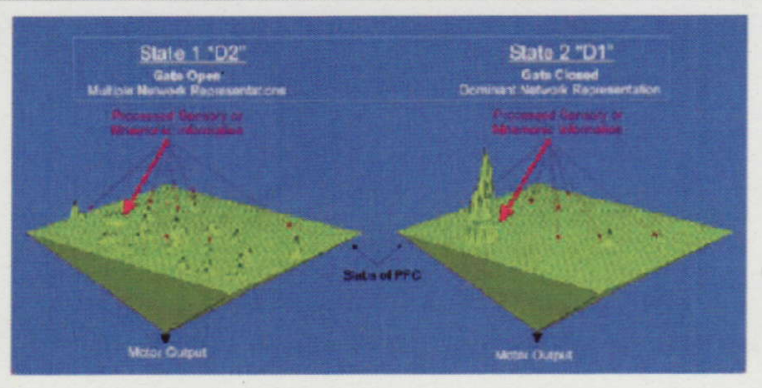

(b)

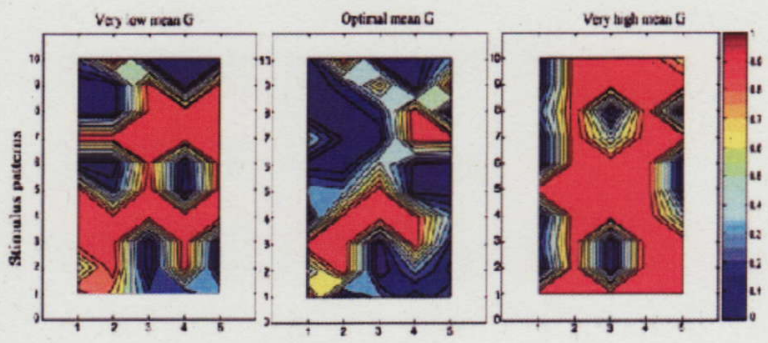

(c)

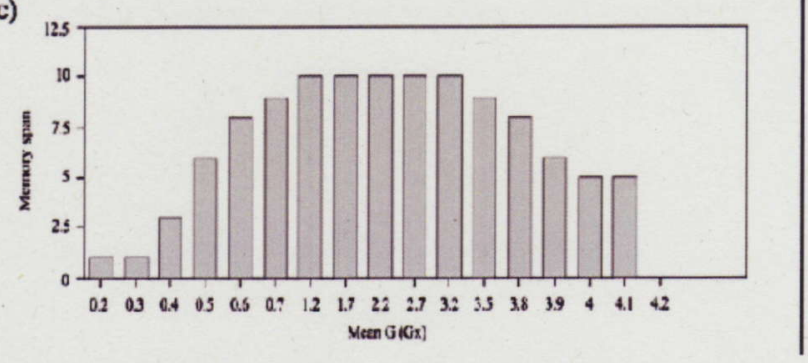


distinctiveness of stored memory items' internal presentations is reduced. Less distinctive representations result in more limited memory span, and account for the aforementioned inverted- $U$ function relating DA signaling to working memory performance ( $\mathrm{Li}$ and Sikström, 2002; see Figure 5.3b and 5.3c).

\section{Changes in DA Systems during Aging}

During the course of normal aging, dopaminergic systems undergo substantial decline (see Figure 5.4 and Table 5.1 for overview). Much of the work on the relationship between aging and DA neurotransmission has focused on the caudate an the putamen-two major nuclei in the striatal complex with dense dopaminergic innervation from the substantia nigra. Thus, the conditions for reliable analyses of DA biomarkers are particularly favorable in the striatum. There is strong evidence for age-related losses of pre- and postsynaptic biochemical markers of the nigrostriatal DA system. Regarding presynaptic mechanisms, both PET and SPECT studies (Erixon-Lindroth et al., 2005; Mozley et al., 2001) indicate marked age-related losses of the DAT in the striatum (see Figure 5.4a), the average decline estimated to be $5-10 \%$ per decade from early to late adulthood. For postsynaptic mechanisms, molecular imaging work reveals age-related losses of both striatal DI (Suhara et al., 1991; Wang et al., 1998) and D2 (Antonini et al., 1993, Nordström et al., 1992) receptor densities of comparable magnitude as found for the DAT (see Figure 5.4a and 5.4b). Age-related decline in receptor density might contribute to dendritic spine loss (Lacor, 2007). An issue for future research to determine is
Table 5-1 Cross-sectional estimates of percentage of decade-by-decade decline in dopamine D2 receptor binding mechanisms in various extrastriatal regions reported in two studies.

\begin{tabular}{lcc}
\hline & Kaassinen et al. 2000 & Inoue et al. (2001) \\
\hline Brain Regions & $\%$ & $\%$ \\
Frontal & 11 & 14 \\
Temporal & 10 & 12 \\
Parietal & - & 13 \\
Occipital & & 12 \\
Hippocampus & 10 & 12 \\
Amygdala & 7 & - \\
Thalamus & 5 & 5 \\
\hline
\end{tabular}

the temporal ordering between age-related changes in DA markers and corresponding anatomical alterations, such as changes in dendritic morphology and grey-matter and white-matter integrity.

A similar downward age trajectory is seen for the mesocortical and mesolimbic dopaminergic pathways. Thus, marked age-related losses in D2 receptor binding have been observed throughout the neocortex as well as in the hippocampus, amygdala, and thalamus. Table 5.1 summarizes cross-sectional estimates of percent reduction per decade in D2 binding efficacy in various extrastriatal regions from two independent studies with Asian and Caucasian samples (Inoue et al., 2001; Kaasinen et al., 2000). Figure 5.4 (c, d)

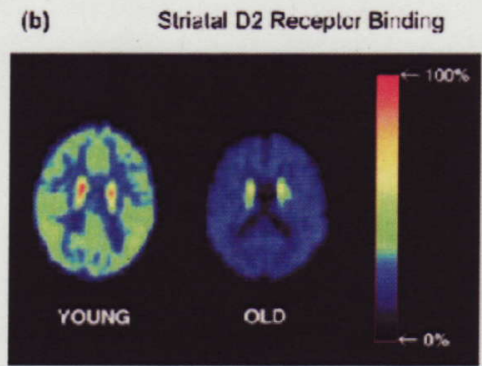

(d)

D2 Receptor binding

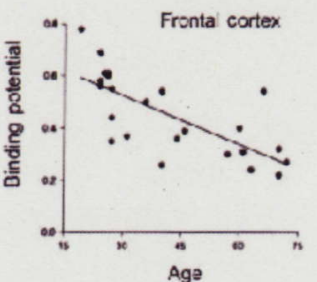

Figure 5-4 Age-related decline in pre- and postsynaptic dopamine binding mechanisms: (a) Striatal DAT binding (Adapted with permission from Erixon-Lindroth et al., 2005; copyright Elsevier.); (b) Striatal D2 receptor binding (Adapted with permission from Kaasinen and Rinne, 2002; copyright Elsevier.); (c) D1 receptor binding in frontal cortex (Adapted with permission from Suhara et al., 1991; copyright Springer-Verlag.); (d) D2 receptor binding in frontal cortex. (Adapted with permission from Kaasinen and Rinne 2002; copyright Elsevier.) 
portrays a decline in D1 and D2 receptor binding in the frontal cortex across the adult lifespan.

The general age-related decline of DA systems may have multiple sources, including neuronal loss in the substantia nigra, loss of synapses, and a decrease of biomarkẹr proteins per neuron with advancing age (see Bäckman et al., 2006 for review). There is an age-related reduction of DA cell bodies in substantia nigra, with an average loss of around 3\% per decade (Fearnley and Lees, 1991). In a unique study, post-mortem cell counts in the substantia nigra were highly related to an ante-mortem imaging marker for DA synthesis capacity (Snow et al., 1993). This suggests that neuronal number influences the total synthesis rate of DA. There is also a reduction of synapses that progresses from childhood through adulthood to old age, which may reflect both adaptive, plastic processes during development and predominantly nonadaptive loss in late life (Gopnic, Meltzoff, and Kuhl, 1999). Finally, there is evidence suggesting an age-related decrease in the number of biomarker proteins per cell. Specifically, work with rodents has demonstrated substantial age-related losses in steady-state levels and synthesis of D2 receptor messenger ribonucleic acid (mRNA; Mesco et al., 1993). Relatedly, human work shows that the agerelated decrease in DAT mRNA may exceed the extent of neuronal loss (De Keyser et al., 1990; Seeman et al., 1987; Severson et al., 1982). Thus, the bottom line is that age-related alterations in neuronal number, synapses, and protein concentrations may all contribute to the general decline of DA systems with advancing adult age.

The fact that similar age patterns are seen for DATs and postsynaptic markers suggests that the expression of transporters and receptors may reflect adaptation of major dopaminergic pathway components. One possibility derived from work on knockout mice is that the loss of DATs initially results in increased DA concentrations; increased DA levels may subsequently lead to down regulation of neurotransmission in postsynaptic neurons (Shinkai et al., 1997; Zhang et al., 1995).

\section{The Correlative Triad: Dopamine, Cognition, and Aging}

So far, we have reviewed evidence indicating (a) a marked negative relationship between adult age and multiple DA markers, and (b) that DA is implicated in a range of cognitive functions. There is also strong evidence of a negative relationship between adult age and performance in tasks assessing various cognitive abilities, including executive functioning, episodic memory, and speed (see Craik and Salthouse, 2007 for reviews). The fact that performance in the very same task domains is influenced by DA functions suggests that there might be a correlative triad among adult age, $\mathrm{DA}$, and cognition. In examining this triad, the key issue is whether alterations in dopaminergic neuromodulation over the lifespan can be empirically linked to age-related cognitive changes. Although relatively few studies have addressed this issue, the data pattern is strikingly consistent.

Wang et al. (1998) reported strong relationships among age, striatal DI receptor binding, and performance in a psychomotor test. Similar results were obtained in a study examining the association between age, striatal D2 receptor binding, and finger-tapping performance (Yang et al., 2003). Although these studies reported bivariate correlations only, the results are important in that they document the correlative triad within the same groups of participants.

In a seminal study, Volkow et al. (1998) assessed striatal D2 binding in conjunction with the testing of executive and motor functioning, as well as perceptual speed across the adult life span. In line with earlier studies (Antonini et al., 1993, Nordström et al., 1992), D2 receptor binding decreased with advancing age and there were negative relationships between age and performance in cognitive tests. Of critical importance, partial correlations revealed moderate-to-strong relationships between D2 binding and cognitive and motor performance, also after controlling for chronological age. These results suggest that age-related decreases in DA function are related to deficits in both cognitive and motor functioning, and that DA activity may influence performance irrespective of age.

These findings were corroborated in a related study (Bäckman et al., 2000) that examined striatal D2 binding and cognitive performance (episodic memory and perceptual speed) in an adult life-span sample. The key finding was that statistical control of D2 binding effectively eliminated the influence of age on cognitive performance, whereas D2 binding contributed to performance over and above that of age (see Table 5.2). The results provide further evidence for the view that DA is implicated in age-related cognitive deficits as well as in cognitive functioning in general.

Other research has extended these findings to presynaptic DA markers such as DATs. Mozley et al. (2001) reported age-related reductions of DATs in the striatum along with age-related deficits in verbal episodic memory. Importantly, striatal DAT binding was

\begin{tabular}{|c|c|c|c|c|}
\hline \multirow[b]{2}{*}{ Regression Variable } & \multicolumn{2}{|c|}{ Tests of Perceptual Speed } & \multicolumn{2}{|c|}{ Tests of Episodic Memory } \\
\hline & Dots & Trial Making A & Word Recognition & Face Recognition \\
\hline \multicolumn{5}{|l|}{ Age First } \\
\hline Age & 0.52 & 0.34 & 0.13 & 0.27 \\
\hline D2 binding & 0.11 & 0.22 & 0.27 & 0.24 \\
\hline Both Age and D2 & 0.63 & 0.56 & 0.40 & 0.51 \\
\hline \multicolumn{5}{|l|}{ D2 Binding first } \\
\hline D2 binding & 0.61 & 0.55 & 0.38 & 0.48 \\
\hline Age & 0.02 & 0.01 & 0.02 & 0.03 \\
\hline Both D2 and Age & 0.63 & 0.56 & 0.40 & 0.51 \\
\hline
\end{tabular}




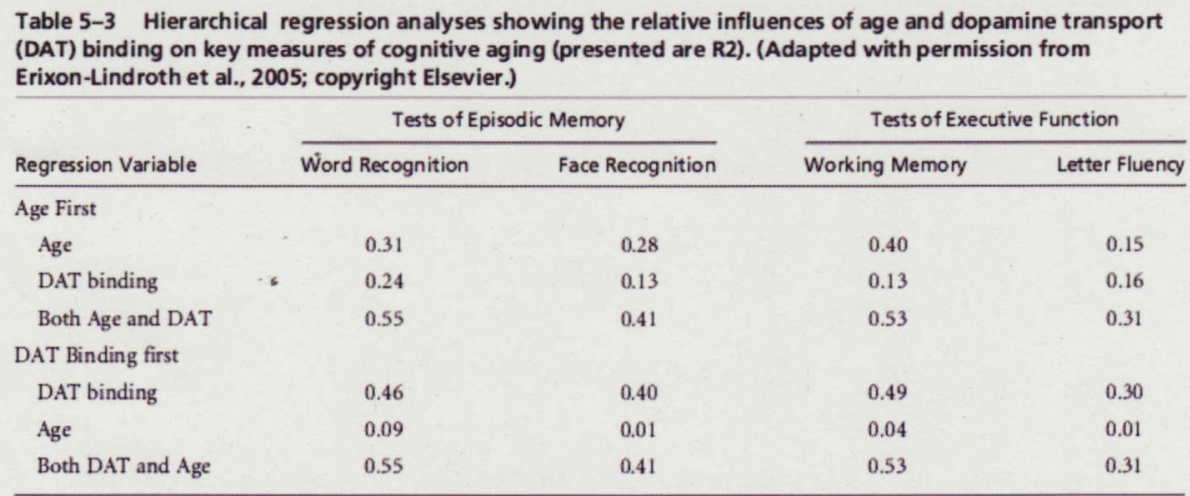

strongly associated with memory performance in both younger and older adults. An age-related decrease of DAT density in the caudate and putamen was also documented by Erixon-Lindroth et al. (2005). This study revealed age-related deficits in tests of episodic memory, working memory, and word fluency, but not in a test of general knowledge. As in the Bäckman et al. (2000) study on D2 receptors, the age-related cognitive deficits were completely mediated by DAT density, although DAT density contributed to the performance variation in memory and fluency independent of age. The latter finding was substantiated by the result that DAT density also was related to performance in the age-insensitive knowledge test (Table 5.3).

Taken together, the available evidence shows that pre- and postsynaptic markers of the nigrostriatal dopamine system are strong general correlates of cognitive performance, as well as powerful mediators of the cognitive changes that occur across adulthood and old age. In light of DA's critical role in age-related cognitive deficits, a range of new research themes and paradigms has recently been proposed for furthering our understanding of the mechanisms through which the DA systems change and affect cognition during aging. In the remainder of this chapter we will highlight some of these new approaches and emerging themes, as well as delineate some outstanding issues for future research on the aging-DA-cognition link.

\section{Emerging Themes and Novel Approaches}

In terms of new themes in cognitive aging research, the issues of (a) whether the relationhip between DA and cognitive deficits is domain-general or function-specific, (b) reduction in adaptive flexibility (or plasticity) when confronted with cognitive challenges or intervention, (c) age-related increases of noise (or fluctuation) in neural and cognitive processes, and (d) changes in decisionmaking processes, could all be linked to age-related declines in dopaminergic modulation. With regard to new research paradigms, genomic imaging and pharmacological intervention approaches are extended to investigate the functioning of the various DA systems. Similarly, multimodal imaging approaches that combine receptor imaging and functional imaging are particularly important for understanding the dynamics of dopaminergic modulation. Below we present these new approaches in turn.

\section{General or Specific Dopaminergic Effects on Cognitive Aging}

Extant evidence seems to suggest that, during the process of aging different aspects of DA systems are similarly affected (Bäckman et al., 2006). In this regard, there is a discrepancy between human and animal research concerning the specificity of the DA-cognition relationship. Studies on aging (Bäckman et al., 2000; Erixon-Lindroth et al., 2005; Volkow et al., 1998), as well as corresponding research on patients with basal ganglia disorders (Bäckman et al., 1997; Lawrence et al., 1998), show that markers of D1, D2, and DAT binding in both the caudate and the putamen show strongrelationships to each other, as well as to cognitive performance. By contrast, dissociative pattems have been found in monkeys both with regard to receptor subtypes as well as regions in the frontostriatal network. For example, Williams and Goldman-Rakic (1995) showed that a DI agonist modulated working-memory fields, whereas a D2 agonist caused changes in the integration of motor and motivational capacities. Wang et al. (2004) found that D2 receptors modulated memory-guided saccades in a workingmemory task, whereas Dl receptors modulated persistent memory-related activity.

To be sure, most of the studies involving primates are based on acute pharmacological challenges, whereas the human studies address interindividual variability over several decades. The possibility for adaptive regulatory mechanisms (Shinkai et al., 1997; Zhang et al., 1995) reducing the chance of finding selective effects is obviously greater in the latter case. Also, in contrast to single-cell recordings, one might question whether the measurement devices in human research (e.g., PET) are sensitive enough to detect potential differences between different DA markers regarding their role in cognitive functions. In particular, it is still difficult to apply PET imaging in a dynamic, event-related sense, which is central for deciphering functional specificities. At the same time, relatively few molecular-imaging studies have addressed the DA-cognition relationship, and the research is characterized by small sample sizes. Thus, the general failure to obtain differential relationships among brain regions as well as different biochemical markers may reflect the limited nature of the database along with low statistical power in individual studies.

Using a sample of middle-aged adults, Cervenka et al. (2008) recently examined whether D2 receptor binding in different regions within the striatal complex are selectively implicated in 

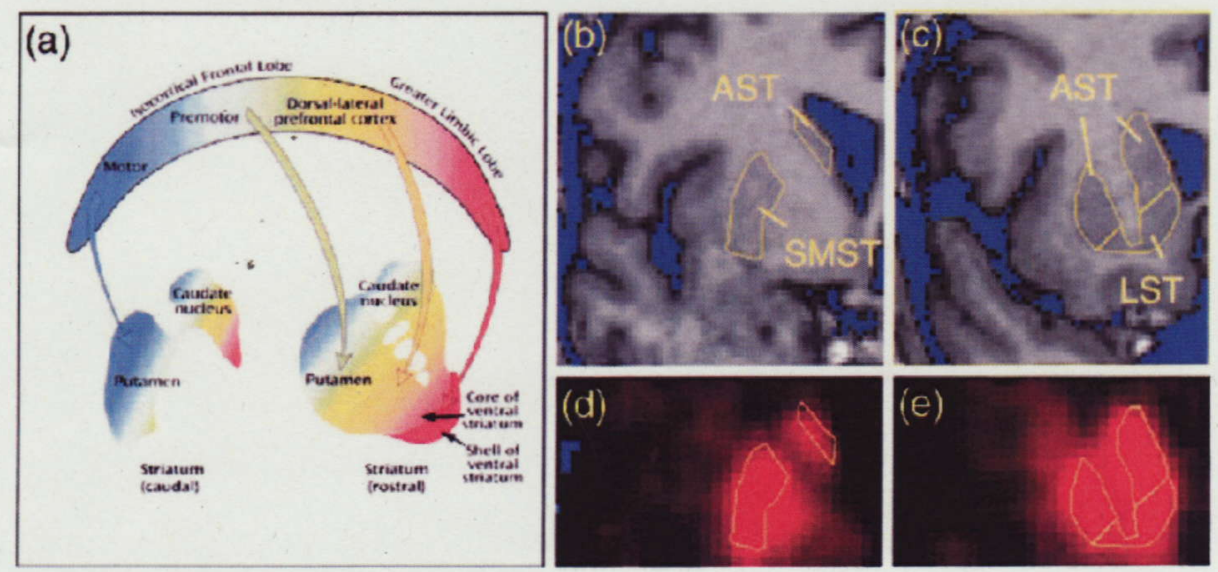

Figure 5-5 (a) A schematic figure of the a natomical connectivity in striatum. (b, c) Coronal MRI sections depicting manually drawn ROIs for striatum in one subject-posterior and anterior to the anterior commissure, respectively. Right hemisphere is showed, left side of the image is lateral. (d, e) Corresponding PET sections showing $[11 \mathrm{C} \mid$ raclopride binding in the same subject, with ROIs superimposed. LST = limbic striatum; AST = associative striatum; and SMST = sensorimotor striatum. (Adapted with permission from Cervenka et al., 2008; copyright Elsevier.)

episodic memory, knowledge, and word fluency. They subdivided the striatum into ventral (nucleus accumbens, ventral caudate, and putamen), associative (mostly caudate, dorsal putamen), and sensorimotor (mostly putamen, dorsolateral caudate) compartments (see Figure 5.5; Alexander, DeLong, and Strick, 1986; Martinez et al., 2003; Parent and Hazrati, 1995). Of chief interest was whether D2 binding in the ventral striatum would be especially critical to episodic memory. Supportive evidence for this hypothesis comes from fMRI research showing that coactivation of ventral tegmentum, nucleus accumbens, and hippocampus strongly predicts episodic recall of reward-related items (Adcock et al., 2006; Wittmann et al., 2005). Relatedly, the BOLD signal in ventral tegmentum has been found to reflect reward probability (D'Ardenne et al., 2008). Furthermore, initial evidence from pharmacological fMRI work in humans and in rodents suggests that $B O L D$ responses increase with drug-induced DA releases in ventral striatum and nucleus accumbens (see Knutson and Gibbs, 2007 for review).

In general, the data from Cervenka et al. (2008) were in agreement with the hypothesis: First, the relationship between ventral striatal D2 binding and episodic memory was stronger than for the other striatal compartments. Conversely, D2 binding in associative and sensorimotor striatum was more strongly related to performance in the knowledge and fluency tasks compared to ventral striatum (see Table 5.4). Thus, these findings extend the fMRI observations (Adcock et al., 2006; Wittman et al., 2005) to the level of neuromodulation and suggest that the striatum, at least in part, may be functionally compartmentalized regarding higherorder cognition. This approach could be extended to brain regions outside the striatum in addressing several important issues. For example, could it be that age-related dopamine losses in a particular brain area (e.g., putamen) are more critical than DA losses in other areas (e.g., frontal cortex, hippocampus) for certain domains of cognitive functioning (e.g., psychomotor speed), whereas the opposite pattern holds true for other cognitive domains (e.g., working memory)? Of interest is also whether potential regional selectivity regarding the DA-cognition link remains the same or is attenuated in aging. The latter outcome would suggest dedifferentiation of the dopamine system in advanced agea pattern that has often been found for various cognitive abilities (Chen, Myerson, and Hale, 2002; de Frias et al., 2007; Grady, 2002; Li et al., 2004; Lindenberger and Baltes, 1994).

\section{DA Release during Cognitive Activity}

Until recently, cognitive performance in molecular imaging studies linking DA functions to cognition was assessed outside the scanner; thus the biomarker (e.g., receptor densities) was related to the off-line cognitive markers (see Cropley et al., 2006 for review). There is, however, emerging evidence for the actual release of dopamine during cognitive activity. A paradigm used to address

Table 5-4 Relationship between D2 binding potential in striatal subregions and cognitive performance (presented are correlation coefficients). (Adapted with permission from Cervenka et al., 2008; copyright Elsevier.)

\begin{tabular}{lccccc}
\hline & $\begin{array}{l}\text { Paired Associate } \\
\text { Learning }\end{array}$ & Word Recognition & $\begin{array}{l}\text { Delayed Pattern } \\
\text { Recognition }\end{array}$ & $\begin{array}{l}\text { Information } \\
\text { Category } \\
\text { Fluency }\end{array}$ \\
\hline Limbic & 0.67 & 0.56 & 0.47 & 0.33 & 0.42 \\
Associative & 0.66 & 0.44 & 0.39 & 0.59 & 0.69 \\
Sensorimotor & 0.50 & 0.29 & 0.24 & 0.48 & 0.72
\end{tabular}


OUP • UNCORRECTED PROOF

this issue involves contrasting DA binding in two conditions varying in cognitive load. DA release is inferred if the BP is lower under the high-load condition compared with the low-load condition. This is so because the binding of the ligand to receptors is supposed to compete more fiercely with endogenous DA when conditions are more cognitively challenging. For instance, an early study showed that the $[11 \mathrm{C}]$ raclopride-labeled $\mathrm{D} 2$ receptor binding in the striatum is reduced when individuals played a video game that required goal-directed motor activities in comparison to the baseline condition (Koepp et al., 1998). More recently, a range of studies using similar paradigms also found reduced DA receptor binding during cognitive activities. Specifically, in young adults there is evidence for DA release in frontal cortex and hippocampus during working-memory performance (Aalto et al., 2005; see Figure 5.6), and evidence for striatal DA release during both card-sorting (Monchi, Ko, and Strafella, 2006) and sequential learning (Badgaiyan, Fischman, and Alpert, 2007).

A recent PET D2 receptor imaging study also showed that caudate BP was sensitive to the demands of cognitive control, suggesting increased endogenous DA release due to increased executive requirements (Sawamoto et al., 2008). However, this task-induced alteration of D2 binding was not observed in Parkinson patients, likely reflecting deficient striatal DA modulation in this disease.

The fact that it is possible to demonstrate DA release in young adults during cognitive activity (Aalto et al., 2005; Badgaiyan, Fischman, and Alpert, 2007; Monchi, Ko, and Strafella, 2006; Sawamoto et al., 2008) opens up the opportunity for interesting age-comparative work on this topic. We know that age-related cognitive deficits are especially pronounced in tasks that require active (executive) stimulus-processing (Craik and Salthouse, 2007). We also know that DA markers are strongly related to performance in executively demanding tasks Bäckman et al., 2000; Erixon-Lindroth et al., 2005; Volkow et al., 1998). Given these observations, we might hypothesize that age differences observed in executively demanding tasks

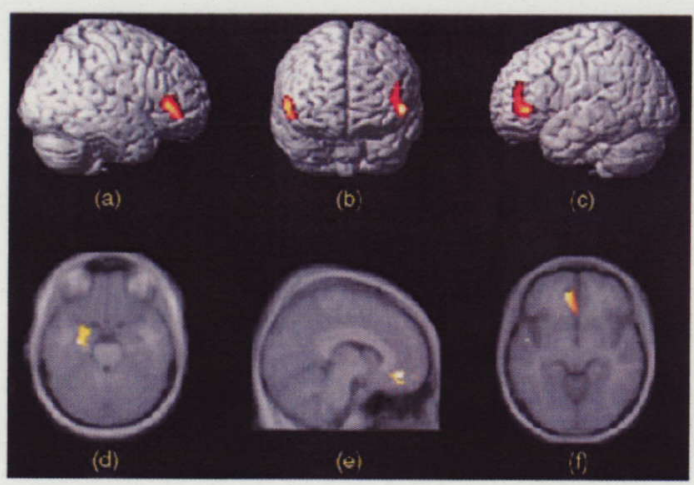

Figure 5-6 Molecular imaging findings of DA release during cognitive activity. Compared with a vigilance task, DA D2 receptor binding (with [11C]FLB 457 as the tracer) decreased during a working memory task bilaterally in the ventrolateral frontal cortex $(\mathrm{a}-\mathrm{c})$ and in the left medial temporal lobe (d). Compared with resting state baseline, both the vigilance task (e) and the working memory task ( $f$ ) induced a decrease in D2 receptor binding in left ventral anterior cingulated. (Adapted with permission from Aalto et al., 2005; copyright Society of Neuroscience 2005.) partly reflect the fact that such tasks require excessive DA release to be successfully performed (Mattay et al., 2003). As a result, age-related DA losses should be particularly detrimental relative to less demanding tasks.

Karlsson et al. (2008) examined this hypothesis by measuring D1 receptor binding in young and old adults while they performed the Multi-Source Interference Task (Bush et al., 2003) compared to that while they were at rest. This task measures the ability to inhibit prepotent responses. Although age-group differences were relatively small, the young outperformed the old with regard to both accuracy and latency. In line with corresponding work on D2 receptors (Aalto et al., 2005; Monchi, Ko, and Strafella, 2006), the young adults showed less binding of the ligand to striatal D receptors during the interference task compared with baseline. This may reflect displacement because of competition with endogenous DA as a function of the cognitive challenge (Laruelle, 2000). The apparent increased release of DA in the young was seen in the ventral, associative, and sensorimotor compartments of the striatum. Most intriguingly, the pattern of data was very different for the old sample, which showed no differences whatsoever in D receptor binding between the two conditions. This null effect suggests unaltered DA release during executive performance in old adults $-\mathrm{a}$ less responsive neurotransmitter system in face of a cognitive challenge.

Another paradigm for examining activity-dependent DA release is cognitive intervention or training research. Animal studies show that habitual exercise increases plasticity of the dopaminergic systems. Specifically, wheel-running training in rats increased tyrosine hydroxylase $\mathrm{mRNA}$ expressions and reduced D2 autoreceptor mRNA in the substantia nigra, as well as increased postsynaptic D2 receptor mRNA in caudate and putamen (Foley and Fleshner, 2008). These results suggest that habitually physically active animals may have an enhanced ability to increase DA synthesis and reduce D2 autoreceptor-mediated inhibition of DA neurons in the nigra, as compared to sedentary animals. Thus far, there is no direct evidence for age-related changes in training or activity-induced DA release in humans. Combining molecular imaging with cognitive intervention, future research should examine whether these findings on activity-dependent plasticity in DA synaptic mechanisms may generalize to humans, and whether the extent of this type of plasticity is affected by aging. To this end, a recent fMRI study on the effects of cognitive training showed that an age-related deficit in task-relevant striatal activation might constrain the transfer of learning in older adults (Dahlin et al. 2008).

Several outstanding issues remain to be investigated in research on DA and cognitive activity. These include the relationship between DA release and BOLD activation in fMRI studies (Knutson and Gibbs, 2007), and how this relationship might change with advancing age. Further, behavioral studies demonstrate that, although young adults typically benefit more than old adults from cognitive training, there is still a sizable cognitive reserve capacity in aging (Hill, Bäckman, and Stigsdotter-Neely, 2000; Nyberg et al., 2003). Thus, it would be of interest to examine whether the negative findings for $D_{1}$ binding in older adults reported by Karlsson et al. (2008) are modifiable through systematic training. Relatedly, investigating training-related changes in transient neurocognitive processes that could be linked to $\mathrm{D}_{2}$ receptors (Bilder et al., 2004), such as updating (O'Reilly, 2006), constitutes an interesting avenue for future research. How the dynamic relationship between transient (D2-related) and sustained (D1-related) DA systems (Grace et al., 2007) might change with age 
and is modulated by genetic background (e.g., COMT status; de Frias et al., 2008) will also be a key issue in cognitive DA research in the years to come.

\section{Deficient Dopaminergic Modùlation and Decreased Processing Robustness}

Recent empirical evidence and theoretical models suggest that increased within-person performance fluctuations flag suboptimal neuronal information processing (see MacDonald, Nyberg, and Bäckman, 2006 for review). Empirically, higher levels of withinperson behavioral variability on sensorimotor, perceptual, and cognitive tasks are often accompanied by lower mean levels of performance, and are indicative of processing alterations associated with aging or pathology (e.g., ADHD, traumatic brain injury, schizophrenia, Parkinson's disease, and dementia; see MacDonald, Nyberg, and Bäckman, 2006 for review). Within-person performance fluctuations (e.g., from trial to trial or session to session in reaction time or memory tasks) increase with advancing age for a variety of cognitive functions ( $\mathrm{Li}$ et al., 2004 ), indicating decreases in processing robustness in late life. Conversely, during child development, performance fluctuations decrease as brain and cognitive functions mature (see Figure 5.7a).
It is critical to note that age-related differences in within-person fluctuations are not simply an artifact of mean-level differences, for these are routinely partialed out in the analysis of within-person variability. On a cognitive level, performance fluctuations are thought to reflect momentary lapses of attentiona failure to exert executive control (West et al., 2002). Consequently, it has been argued that the frontal lobes may be particularly crucial for maintaining stability, hence minimizing performance fluctuations (Stuss et al., 2003). The fact that patients with frontotemporal dementia show higher performance fluctuation than Alzheimer patients at the same severity level (Murtha et al., 2002) supports this contention. Furthermore, longitudinal data demonstrate that older adults who exhibit higher withinperson fluctuations declined more in executive functioning over several years than their more stable counterparts (see Figure 5.7b; Lövdén, Li, Shing, and Lindenberger, 2007).

Of specific interest here is the link between dopaminergic modulation and processing fluctuation observed at the behavioral and neuronal levels. Animal studies have shown that DA receptor reductions, as observed during aging, not only slow down performance but also increase performance variability (MacRae, Spirduso, and Wilcox, 1988; Schultz et al., 1989). Prefrontal broadband noise derived from electroencephalogram (EEG) is increased in patients with schizophrenia, a condition marked by
Figure 5-7 (a) Lifespan age differences in processing robustness as measured by the inverse of fluctuations in cognitive reaction times. Olde adults and children show less robust processing. (Adapted from Li et al., 2004 with permission; copyright Blackwell 2004.) (b) Individual differences in processing robustness predict 13-year longitudinal decline in executive functioning measured by the category fluency test. (Adapted from Lövdén et al., 2007 with permission; Copyright Elsevier Science 2007.) (a)

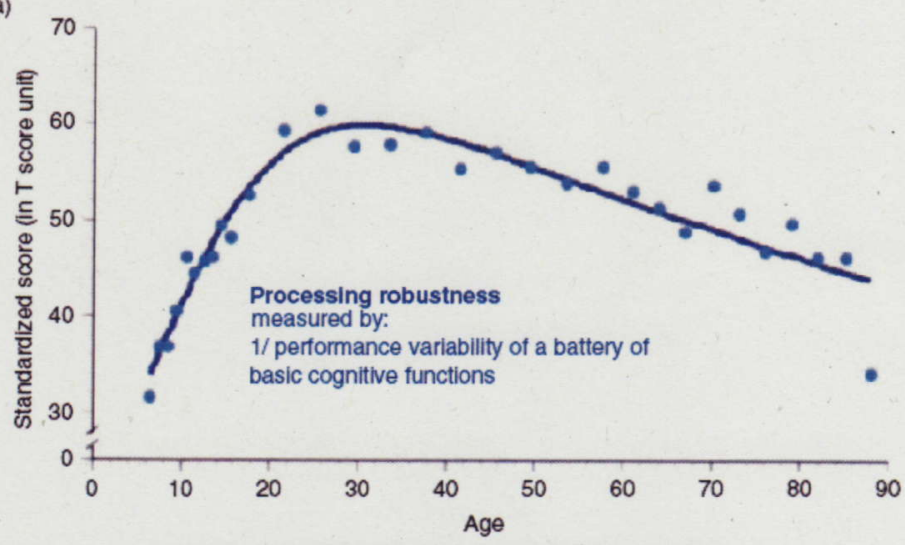

(b)

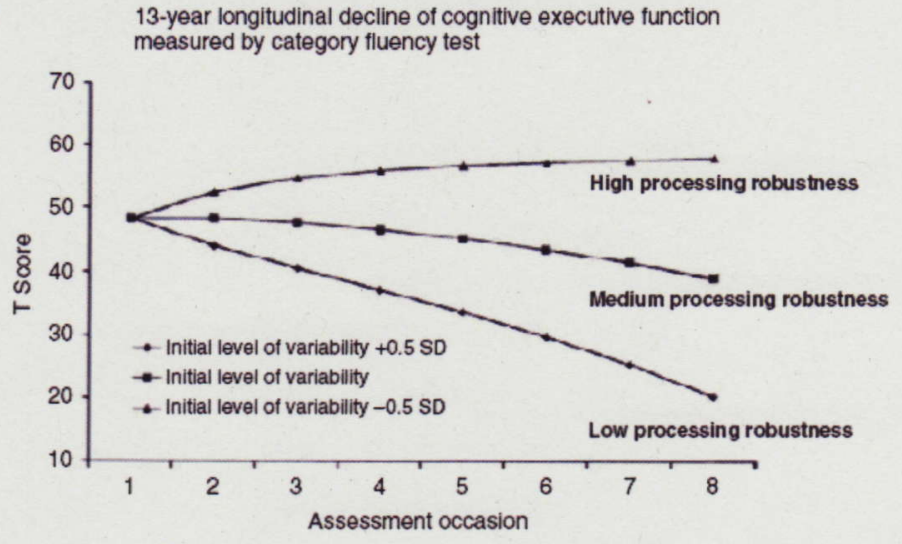


dysfunctional dopaminergic neuromodulation. A review of more recent findings concludes that those groups of individuals who exhibit high performance fluctuations are often characterized by alterations in DA functions (MacDonald, Nyberg, and Bäckman, 2006). Indeed, neurocomputational work on $\mathrm{DA}$, aging, and cognition suggests that reduced DA activity increases neuronal noise and results in less distinctive internal representations of percepts of memory items, which, in turn, leads to increased performance fluctuations (Li, Lindenberger, and \$̧ikström, 2001) and altered dynamics of interactions between extrinsic neuronal noise and perceptual noise (Li, von Oertzen, and Lindenberger, 2006).

In the first attempt to directly link $\mathrm{DA}$ to processing fluctuations, MacDonald et al. (in press) measured extrastriatal D2 binding in the anterior cingulate, frontal cortex, and hippocampus in a middle-aged group. Processing fluctuation was assessed in terms of within-person variability in reaction time during episodic memory retrieval and concept formation. Because the sample was relatively age-homogeneous, between-person differences in D2 binding and processing fluctuation were relatively small. Nevertheless, there were systematic negative correlations between D2 binding and processing fluctuation across all three brain regions examined ( $r$ ranging from -.30 to -.45 ). Thus, these data indicate that, even within normal ranges, reduced availability of DA may result in more fluctuating behavior.

In a related vein, polymorphisms of the gene coding for catechol $O$-methyltransferase (COMT), which catabolizes DA in the frontal cortex, are systematically related to performance variability. As noted, relative to monozygotic carriers of the met allele of COMT, the degradation rate of DA in the synaptic cleft is about three to four times faster in monozygotic carriers of the val allele (Lotta et al., 1995), who also show higher noise levels in EEG (Winterer et al, 2004) and fMRI (Winterer et al., 2006) brain signals during perceptual and cognitive tasks. In line with these findings, recent genomic studies with young adults show that reaction times while performing simple cognitive tasks fluctuated more in COMT val homozygotes than in met homozygotes (Stefanis et al., 2005). These studies suggest that future research could benefit from combining individual differences in genetic predispositions for DA signaling with behavioral and imaging studies to more directly examining the relationship between deficient dopaminergic modulation and reduced processing robustness in old age. In this context, the computational approach of stochastically reducing the slope of the sigmoidal activation to simulate aging-related decline in dopaminergic modulation (Li, Lindenberger, and Sikström, 2001) suggests that increased processing fluctuation may contribute to age-related decline in perceptual decision making. More specifically, as aging or individual differences in genetic polymorphisms affecting neuromodulation may lead to suboptimal gain modulation of neuronal signal-to-noise ratio (Figure Figure 5.8a), the extent of random processing fluctuation increases (Figure $5.8 \mathrm{~b}$ ). This results in less distinctive perceptual representations (Figure 5.8c). Future studies

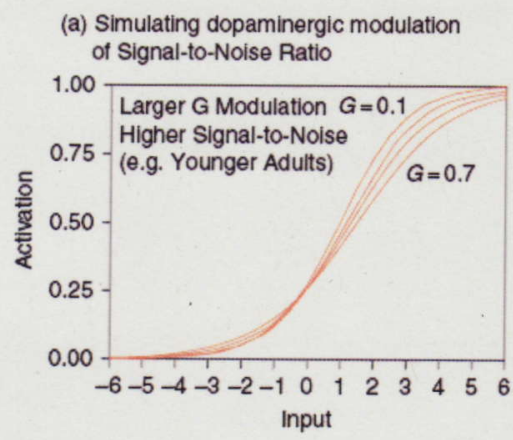

(b \& c) Functional outcomes on:
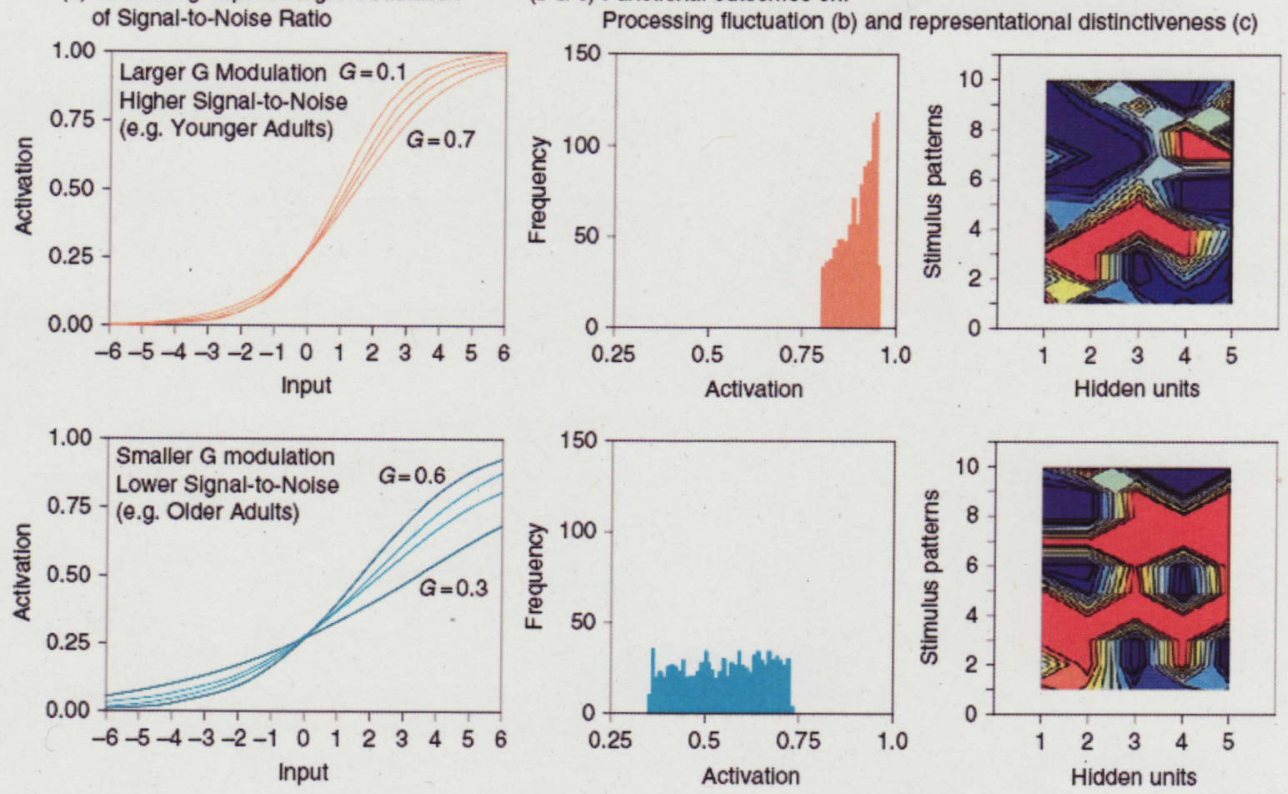

Figure 5-8 Schematic diagram relating functional effects of dopaminergic modulation of neuronal noise to processing char acteristics of evidence accumulation. (a) The role of DA in affecting neuronal signal-to-noise ratio is modeled by the gain parameter (G) of the sigmoidal activation function (Li, Lindenberger, and Sikström, 2001; Servan-Schreiber et al., 1990). The neuronal input-response mapping functions of individuals with optimal dopamingeric modulation because of advantageous DA genotype are captured by steeper activation functions with higher $\mathrm{G}$ and signal-to-noise ratio. (b) G modulation of signal-to-noise ratio results in less random activation variability in networks simulating optimal DA modulation and greater variability in networks simulating suboptimal DA modulation. (c) The internal stimulus representations are more distinctive (with fewer units overlapping in representing different stimuli) in networks with optimal DA modulation than in networks with suboptimal DA modulation. (Adapted with permission from Li et al., 2001; copyright Elsevier.) 
should directly examine the interactions between individual differences in DA-relevant genotypes and aging-related deficits in dopaminergic modulation on processing fluctuation and the distinctiveness of neural representations underlying perception and memory.

\section{Dopamine, Aging, and Decision Making}

During the past decade, evidence from research at neurophysiological, neuroimaging, and behavioral levels has converged on the view that perception and cognition are gradual processes of evidence accumulation amidst noisy sensory information and signal processing. According to this view, perceptual decisions (e.g., deciding whether a human face or a physical object, such as a house, was seen) are made by accumulating sensory information until a threshold is reached, at which point the decision process concludes and a motor response is elicited (Heekeren, Marrett, and Ungerleider, 2008 for review; see Figure 5.9). Moment-to-moment fluctuations in the sampling of evidence for choice options reflect noise in the sensory input as well as in the decision process. Formal sequential sampling models of sensory evidence accumulation account for memory and decision performance, and related biophysical models link ramping neuronal firing rates with rates of sensory information integration. Single-cell recording studies in monkeys, as well as human EEG and fMRI research, provide support for these models (Heekeren, Marrett, and Ungerleider, 2008).
Sequential sampling models of perceptual decision-making postulate that signal processing is inherently noisy (see Bogacz, 2007 for review). However, noise is typically treated as a primitive in these models, and the neurobiological mechanisms affecting its properties and functional consequences for cortical dynamics are left unspecified. As indicated by empirical and computational findings reviewed above ( $\mathrm{Li}$ et al., 2001; Serven-Schreiber et al., 1990; Winterer \& Weinberger, 2004), DA's noise-tuning function may affect the quality of perceptual representations, which underlie perceptual decisions.

Hence, three strands of evidence for (a) pervasive decline in dopaminergic modulation during aging, (b) DA's noise-tuning effect on perceptual decision-making, and (c) DA's influences on reward-based decision-making (see Schultz, 2006 for review) suggest a possible triadic relationship between aging, neuromodulation, and reward-based decision-making ( $\mathrm{Li}$ et al., 2007). Currently, there is limited evidence on neurofunctional correlates of reward-based decision-making in the context of aging. Using a probabilistic object reversal task, Mell et al. (2005) found deficits in instrumental learning in older adults. Compared to younger adults, older adults collected fewer reward points throughout the task and needed more trials to learn the stimulus-response associations. In a subsequent fMRI study, the poor behavioral performance in older adults was linked to reduced brain activation in ventral striatum (Marschner et al., 2005; Mell et al., 2005). Relatedly, Larkin et al. (2007) found that younger and older adults differed in both selfreported and neural responsiveness to anticipated monetary gains
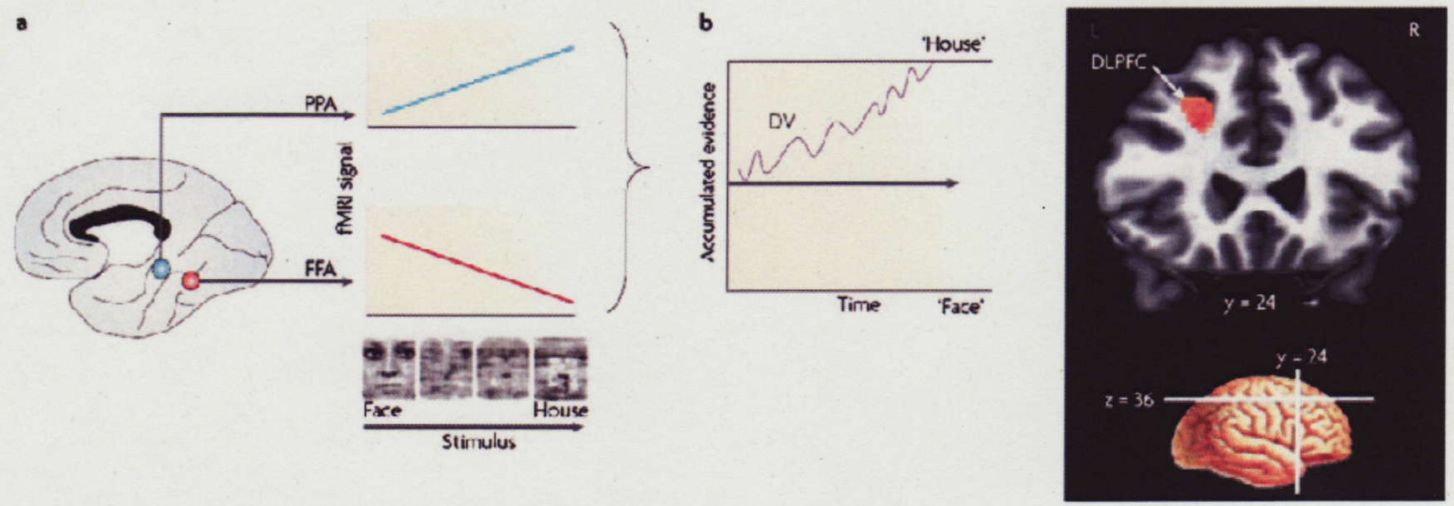

Figure 5-9 Representation of sensory evidence in low-level sensory regions and perceptual decision-making in the posterior dorsal lateral prefrontal cortex. (a) Schematic diagram of the representation of sensory evidence in category-selective brain regions. When participants had to decide whether an image was a face or a house, there was a greater response in face-selective regions (the fusiform face a rea (FFA) -red line) to clear images of faces than to degraded images of faces. In addition, house-selective brain regions (the parahippocampal place area (PPA)) showed a greater response to clear images of houses than to degraded images of houses (blue line). (b) The comparison of sensory evidence in higher-level brain regions. Neurophysiological data, as well as modeling studies, suggest that a decision variable is computed by comparing the output of pools of selectively tuned lower-level sensory neurons. In this example, the output of category-specific brain regions (the FFA and the PPA) is integrated over time. The decision variable (DV) drifts between the two boundaries and once one of them has crossed, the corresponding decision is made (here, 'house'). (Adapted from Heekeren, Marrett, and Ungerleider, 2008, with permission; copyright Nature Publishing Group 2008.) 
and losses. Specifically, older adults exhibited intact striatal and insular activation during gain anticipation, but reduced activation during loss anticipation. Although these studies did not directly examine the impact of aging-related decline in dopaminergic modulation in affecting reward-based decision-making, DA's involvement can be inferred given the rich dopaminergic innervation in the striatum and related regions relevant to reward processing.

\section{DA-relevant Genes and Cognittion: Magnified Effects in Old Age}

Genetic polymorphisms relevant for DA synthesis, catabolism, presynaptic and postsynaptic effects have been identified and their functional consequences are currently under intense investigation (see Green, Munafo, and DeYoung, 2008; Mattay et al. 2008; Meyer-Lindenberg and Weinberger, 2006 for reviews). As noted in previous sections, allelic variations in COMT genotype have been linked to cognitive performance, with met carriers (higher dopamine availability in $\mathrm{PFC}$ ) outperforming val carriers (lower DA availability in PFC; see Goldberg and Weinberger, 2004 for review). In studies with younger adults, however, effect sizes are small and findings are inconsistent (see Barnett et al., 2007 for meta-analytic evidence). Relatively few studies have assessed the effects of the COMT genotype on cognition in aging. The available evidence, however, suggests a more robust advantage of met carriers in late adulthood (de Frias et al., 2004, 2005; Harris et al., 2005; O'Hara et al., 2006; Starr et al., 2007). A magnification of gene- related COMT effects on cognitive performance should, in fact, be expected on the basis of the inverted U-shaped function relating DA levels to cognition (Cai and Arnsten, 1997; Li, Lindenberger, and Sikström, 2001; Li and Sikström, 2002). Specifically, as aging results in marked DA losses, the inverted $U$-shaped curve implies that the cognitive difference between older met and val carriers of the COMT gene is greater than that between younger met and val carriers (Lindenberger et al., 2008; Figure 5.10).

Nagel et al. (2008) tested this hypothesis directly in a recent large-scale study. Using two measures that draw heavily on frontal

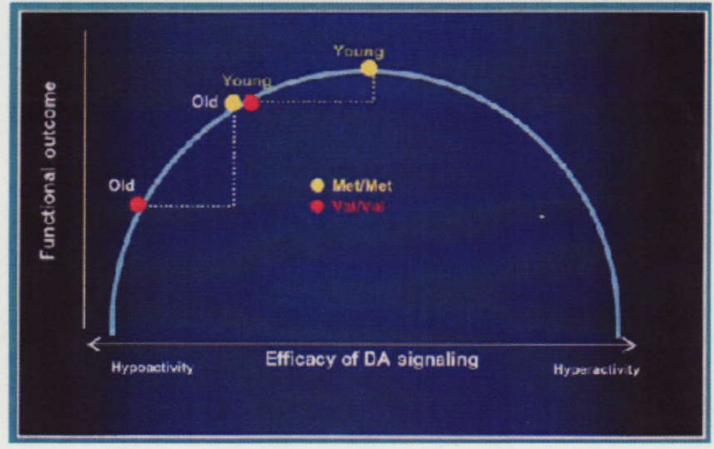

Figure 5-10 An inverted U-shaped function linking the strength of frontal DA signaling in early vs. late adulthood to performance. The shape of the curve implies that the difference in performance between older met and val carriers is greater than the difference between younger met and val carriers of the COMT gene. (Adapted with permission from Nagel et al., 2008; copyright Frontiers of Human Neurosciences.)

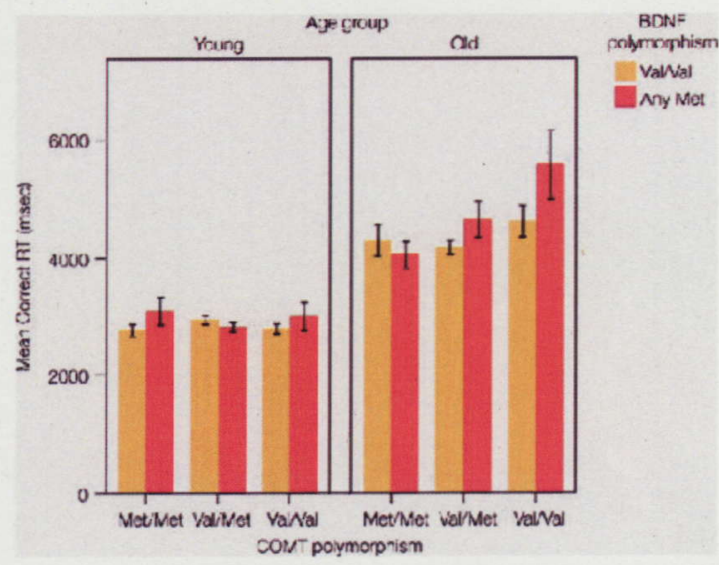

Figure 5-11 Mean reaction for correct WCST responses as a function of age, COMT, and BDNF genotype. The age $\mathrm{x} C O M T$ interaction accounted for $4.1 \%$, and the age $x$ COMT x BDNF interaction for $3.1 \%$ of the variance (Adapted with permission from Nagel et al., 2008; copyright Frontiers of Human Neurosciences.)

integrity, the Wisconsin Card Sorting Test (WCST), and a test of spatial working memory, Nagel et al. (2008) demonstrated COMT genotype $\mathrm{x}$ age interactions in the expected direction: Whereas differences between met and val carriers were small or nonexistent in the young sample, a met advantage was observed in the old sample. Furthermore, the effect of COMT genotype not only interacted with age but also with the gene coding for brain-derived neurotrophic factor (BDNF). Older adults carrying two COMT $\mathrm{Val}$ alleles and at least one BDNF Met allele took particularly long time to respond, resulting in an age $\mathbf{x}$ gene $\mathbf{x}$ gene interaction (see Figure 5.11). Thus, although genetic status does not change across adulthood, the functional effects of genotype variation may change because of age-related constraints on brain resources, such as deficits in various aspects of DA modulation (Lindenberger et al., 2008).

In addition to the COMT gene, effects of genes affecting the DAT, as well as different receptors (e.g., DRD1, DRD2, and DARPP-32) on cognitive aging at the brain and behavioral levels, are interesting avenues for further investigation of the mechanisms through which deficits in different components of the DA systems affect cognitive aging (Deary et al., 2004; Mattay et al., 2008).

\section{Pharmacological Intervention}

In young adults, DA agonists typically enhance performance (Luciana and Collins, 1997), whereas DA antagonists impair performance (Ramaekers et al., 1999) across a variety of cognitive tasks. Furthermore, consistent with the inverted U-shaped function, the effects of DA on cognition and brain activity seem to be modified by COMT genotype, such that val carriers (lower baseline DA levels) show a more efficient frontal response, whereas met carriers (higher baseline DA levels) show a less efficient frontal response following administration of a DA agonist (Mattay et al., 2003). These patterns of data open up for a series of interesting research questions regarding the role of DA 
in cognitive aging. Preliminary answers are emerging for some of these questions.

First, we may ask whether dopamine antagonists, in addition to lowering performance, might lead to a pattern of brain activation during cognitive performance (e.g., working memory) in young adults that resembles that which is typically exhibited by older adults under placebo conditions (e.g., more diffuse activation). In an fMRI study, Fischer et al. (2008) addressed this issue by examining whether brain activation patterns in young adults under the influence of a dopaminergic antagonist during a spatial working memory task would resemble those of older adults under normal conditions. Three groups were studied: young-placebo (YP), young-antagonist (YA), and old-placebo (OP). Two initial findings from this study provide support for this assumption. First, the YP group showed greater activity in task-relevant frontal and parietal regions than the YA and OP groups. Second, the two latter groups showed more widespread activity in regions associated with expenditure of effort to cope with the task demands (e.g., anterior cingulate cortex, cerebellum). These preliminary findings may reflect the fact that depletion of DA (whether ontogenetically or pharmacologically) decreases the signal-to-noise ratio in relevant networks, resulting in lowered neural efficiency.

We may also ask whether a dopamine agonist would alter the brain activation patterns of older people in the opposite direction (i.e., more specific and associated with better performance). This research issue may profit from considering COMT gene-related differences in DA signaling. On the basis of the inverted U-shaped relationship between DA levels and cognitive/brain function, older val carriers may be expected to exhibit the largest cognitive improvement and the most pronounced increase in neural efficiency from a DA agonist. Young val carriers and older met carriers may also show some improvement, whereas young met carriers may deteriorate, because their initially high dopamine levels lead to suboptimally high dopamine levels in conjunction with a dopamine agonist (cf. Mattay et al., 2003). Evidence that speaks to these issues is on its way.

\section{Methodological Fusion: Multimodal Imaging}

Research on neuromodulation of cognition and how this link is affected by aging has produced many exciting findings, with new possibilities for methodological fusion. Molecular imaging techniques are suitable means for investigating pre- and postsynaptic DA system mechanisms, whereas functional neuroimaging techniques provide evidence on neural circuitries engaged during cognitive processing. Further, more than half of the genes in the human genome are expressed in the brain (Hariri and

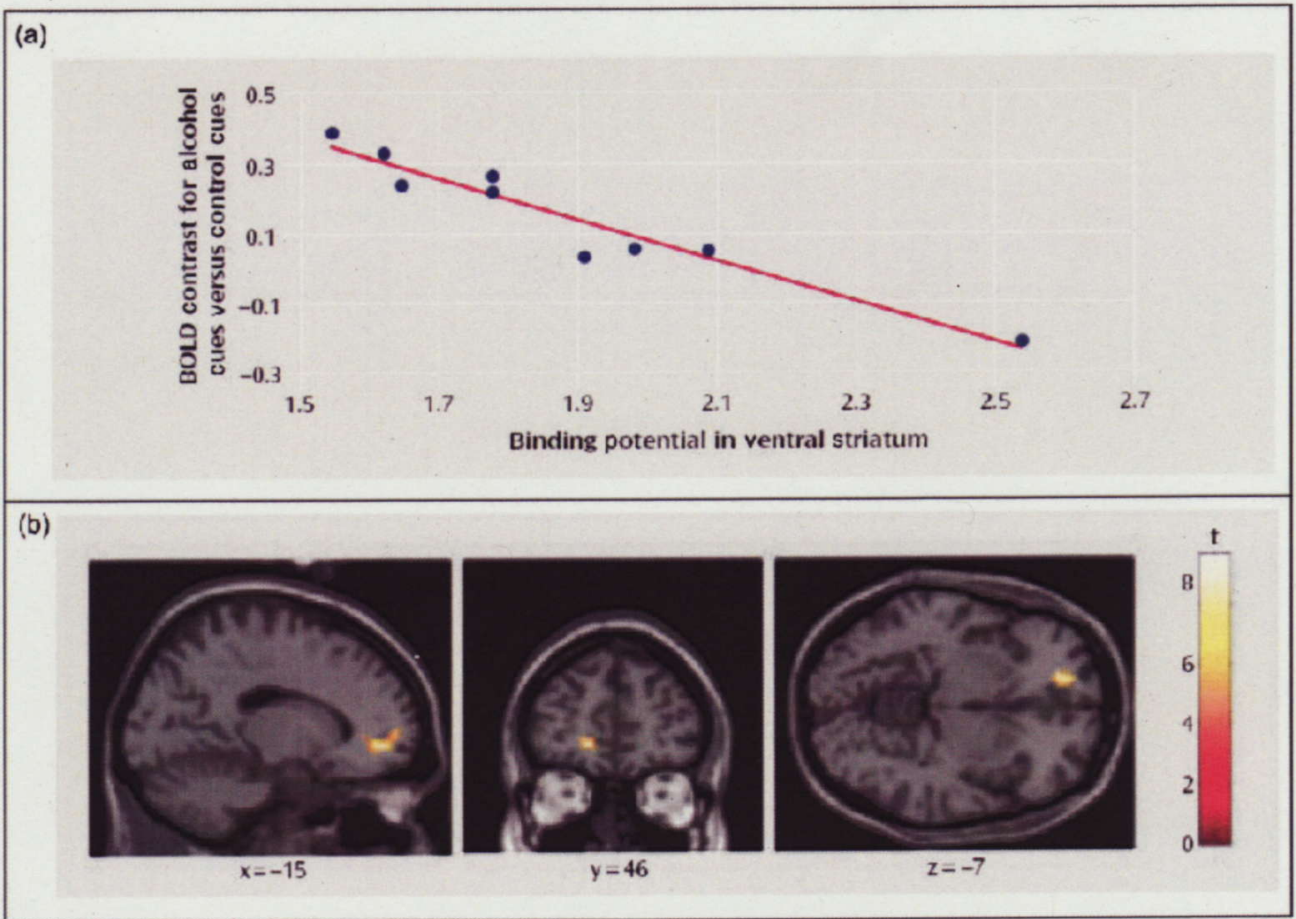

Figure 5-12 Findings from a multimodal imaging study of the dopaminergic modulation of addiction. Panels (a) and (b) show a scatterplot and the localization, respectively, of the correlation between D2 receptor binding potential in ventral striatum and functional brain activation elicited by alcohol-associated stimuli, beyond the activation produced by abstract and neutral control stimuli in the left medial prefrontal cortex of the alcoholics. (Adapted with permission from Heinz et al., 2004; copyright American Psychiatric Publishing.) 
OUP • UNCORRECTED PROOF

Weinberger, 2003; Meyer-Lindenberg and Weinberger, 2006). Thus, multimodal imaging approaches combining molecular imaging and functional imaging can be further augmented with candidate gene association research to study age-related differences in dopaminergic modulation of cognition. By collecting PET-based data on pre- or postsynaptic mechanisms of the DA systems and functional imaging data during cognitive activity on the same individuals, age-related differences in the relationship between neurotransmission and functional brain activation can be more directly investigated.

Multimodal imaging approaches have been applied in the context of psychiatric research. For instance, by combining PET imaging of D2 receptors (with the benzamide radioligand $\left.\left[{ }^{18} \mathrm{~F}\right] \mathrm{DMFP}\right)$ and $\mathrm{AMRI}$ of alcohol cue-related brain activity, Heinz et al. (2004) showed that D2 BP in the nucleus accumbens and ventral striatum is correlated both with the behavioral measures of alcohol craving and functional brain activation elicited by alcohol cues in the medial prefrontal cortex (see Figure 5.12). More recently, Meyer-Lindenberg et al. (2007) combined individual differences in genetic polymorph ism (DARPP-32) affecting D1 receptors in striatum with structural MR and PMRI, and showed that the DARPP-32 gene affects striatal volume and functional activation, as well as connectivity to the prefrontal cortex in schizophrenic patients.

Outside the context of clinical research, Schott et al. (in press) used PET imaging of D2 receptors (with [11C]raclopride) and fMRI to examine the relationship between DA release in ventral striatum and reward-related functional brain activity in the same brain region. Consistent with the view that DA agonism affects the BOLD signal (Knutson and Gibbs, 2007), Schott et al. (in press) observed a strong relationship between striatal DA release and the magnitude of the BOLD response.

In another recent study in a group of middle-aged and older adults, Landau et al. (2008) found that a PET marker of DA synthesis capacity was related to load-dependent PFC activation during a working-memory task, corroborating the point that dopaminergic neurotransmission is related to PFC-related functions. Extending the DA-BOLD relationship to the domain of episodic memory, Nyberg et al. (2008) showed a positive association between striatal D2 binding and BOLD activation in the lateral prefrontal cortex during a long-term memory updating task in a sample of healthy older adults (Nyberg et al., 2008). How the relationship between PET-derived indicators of DA activity and functional brain activation might change over the life course, and the extent to which these changes are modulated by other age-associated neurochemical changes and genetic background, constitute key questions for future research.

\section{Interactions Between DA and Other Transmitters and Epistasis Between DA-related Genes}

In addition to the dopaminergic systems, future theoretical and empirical work should consider other transmitter systems, such as the glutamatergic system. NMDA receptors interact with DA in regulating PFC-related cognitive functions (see Castner and Williams, 2007 for review) and there is also recent evidence that the COMT polymorphism and the glutamate receptor 3 gene (GRM3) interact in affecting working memory functions in the PFC (Tan et al., 2007). Delineating the interactions between different transmitter systems would require investigations that encompass multiple genes linked to multiple transmitter systems. The degree to which these interactions change across adulthood is a major issue in future research in the cognitive neuroscience of aging.

Computational theories may be helpful in exploring the complex interactions between multiple systems. For instance, some aspects of the interactions between NMDA and DA receptors have been modeled in a two-state model dopaminergic modulation of neuronal representations in the PFC (Durstewitz, Seamans and Sejnowksi, 2000), where D1 receptor modulation results in longlasting NMDA currents and increased inhibition that sharpens memory representations. On this basis, predictions of the interactions between DA and NMDA in affecting age differences in working memory functions can be mapped onto individual differences in genotype profiles with respect to, for example, D1, D2, and NMDA receptors. Specifically, individuals with similar D2 and NMDA receptor genotypes who differ in Dl receptor type may express different brain functional and behavioral patterns with respect to the exploration and filtering states of working memory processing, and these differences may increase with advancing age.

In addition to DA's interactions with other transmitters, the different components of DA modulation (e.g., synthesis, presynaptic and postsynaptic mechanisms) also influence each other in affecting cognitive functioning. Recent findings indicate that the COMT and DAT genes interact with each other in affecting hippocampal memory functions (Bertolino et al., 2008) and reward processing (Yacubian et al., 2007); the extent to which these interactions change during the aging process remains unknown.

\section{Interactions Between Neurochemical and Anatomical Aging}

The general decline of DA systems with advancing adult age, which commences in early adulthood and comprises declines in receptors may affect dendritic loss (Lacor, 2007) and trigger or accentuate other physiological changes in the aging brain, such as grey matter loss, by compromising the functional integrity of subcorticalcortical connections. Consistent with this hypothesized trajectory of age-related brain changes, evidence suggests that alterations in various DA biomarkers may have an earlier onset and progress more rapidly across the lifespan compared to changes in gray or white matter (Bäckman et al., 2000; Raz et al., 2000). The temporal relation between changes in transmitter systems and anatomical alterations of the aging process could be directly addressed by longitudinal studies combining MR-based measures of regional volumes and structural connectivity with PET-based measures of transmitter availability.

\section{Concluding Remarks}

Fifty years after the discovery of DA as a neurotransmitter, much is now known about its critical involvement in a wide range of cognitive functions. Theoretical and recent empirical evidence converge to suggest that DA's influence on various cognitive functions (e.g., working memory, reward processing, and processing robustness) may be traced back to its basic role in affecting neural signal transduction (Girault and Greengard, 2004), such as by modulating the signal-to-noise ratio of neural gain function (Cohen and Servan-Schreiber, 1992; Li, Lindenberger, and 
Sikström, 2001). Furthermore, much is also known about how the different DA components decline during usual and pathological aging. With recent methodological advances in molecular imaging, various components of the DA systems can now also be scrutinized in great detail.

Capitalizing on these developments, research on dopaminergic modulation of human cognitive aging is currently in an unprecedented exciting phase, empowered with genomic, molecular, and functional , brain-imaging technologies. Age-comparative studies combining genomic approaches with multimodal imaging will be able to investigate the effects of aging on the DA-cognition association at multiple levels, by cross-linking genetic influences on the various components of the DA systems with measures of receptor binding efficacy and functional brain activity. In addition, given that the DA systems are not acting in isolation in affecting brain and cognitive processes, future research should also systematically investigate the interactions between DA and other transmitters, for instance, serotonin, glutamate, and gamma-aminobutyric acid (GABA), that are relevant to aging and cognition. In addition to working memory, the most commonly investigated DA modulated cognitive function, there is emerging interest in the influences of DA modulation on: (a) the robustness of the aging cognitive system, (b) aging-related limits in cognitive plasticity (e.g., altered transient response to cognitive challenges or reduced long-term enhancement from cognitive intervention), and (c) aging-related differences in reward-based decision-making subserving goal-directed behavior. In conclusion, by combining new methodologies that allow the integration of $\mathrm{DA}$ modulation of aging and cognition at various levels with the broadening of investigated phenomena, the perspectives for future research on DA modulation of cognitive aging will be both deepened and widened.

\section{References}

Aalto, S., Brück, A., Laine, M., Nảgren, K., and Rinne, J. O. (2005). Frontal and temporal dopamine release during working memory and attention tasks in healthy humans: A PET study using the high-affinity dopamine $\mathrm{D}_{2}$ receptor ligand $[\mathrm{nC}] \mathrm{FLB}$ 457. Journal of Neuroscience, 25: 2471-2477.

Adcock, R. A., Thangavel, A., Whitfield-Gabrieli, S., Knutson, B., and Gabrieli, J. D. E. (2006). Reward-motivated learning: Mesolimbic activation precedes memory formation. Neuron, 50 : $507-517$.

Alexander, G. E., DeLong, M. R., and Strick, P. L. (1986). Parallel organization of functionally segregated circuits linking basal ganglia and cortex. Annual Review of Neuroscience, 9: 357-38.

Antonini, A., Leenders, K. L., Reist, H., Thomann, R., Beer, H.-F., and Locher, J. (1993). Effect of age on $D_{2}$ dopamine receptors in normal human brain measured by positron emission tomography and [nC] raclopride. Archives of Neurology, 50: 474-480.

Bäckman, L. and Farde, L. (2005). The role of dopamine functions in cognitive aging. In R. Cabeza, L. Nyberg, and D. C. Park (eds), Cognitive Neuroscience of Aging: Linking Cognitive and Cerebral Aging (pp. 58-84). New York: Oxford University Press.

Bäckman, L., Ginovart, N., Dixon, R. A., Robins Wahlin, T. B., Wahlin, Ả., Halldin, C., and Farde, L. (2000). Age-related cognitive deficits mediated by changes in the striatal dopamine system. American Journal of Psychiatry, 157: 635-637.

Bäckman, L., Nyberg, L., Lindenberger, U., Li, S.-C., and Farde, L. (2006). The correlative triad among aging, dopamine, and cognition: Current status and future prospects. Neuroscience and Biobehavioral Reviews, 30 : 791-807.

Bäckman, L., Robins-Wahlin, T.-B., Lundin, A., Ginovart, N., and Farde, L. (1997). Cognitive deficits in Huntingtońs disease are predicted by dopaminergic PET markers and brain volumes. Brain, 120: 2207-2217.
Badgaiyan, R. D., Fischman, A. J., and Alpert, N. M. (2007). Striatal dopamine release in sequential learning. Neurolmage, 38: 549-556.

Barnett, J. H., Jones, P. B., Robbins, T. W., and Müller, U. (2007). Effects of the catechol-O-methyltransferase $\mathrm{Val} / 158 \mathrm{Met}$ polymorph ism on executive function: A meta-analysis of the Wisconsin Card Sorting in schizophrenia and healthy controls. Molecular Psychiatry, 12: 502-509.

Bertolino, A., Giorgio, D. A., Blasi, G., Sambataro, F., Caforio, G., Sinibaldi, L. et al. (2008). Epistasis between dopamine regulating genes identifies a nonlinear response of the human hippocampus during memory tasks. Biological Psychiatry, 64: 226-234.

Bilder, R. M. Volavka, I., Lachman, H. M., and Grace, A. A. (2004). The catechol-O-methyltransferase polymorphism: Relations to the tonicphasic dopamine hypothesis and neuropsychiatric disorders Neuropsychopharmacology, 29: 1943-1961.

Björldund, A. and Dunnett, S. B. (2007). Dopamine neuron systems in the brain: An update. Trends in Neuroscience, 30: 194-202

Bogaci, R. (2007) Optimal decision-making theories: Linking neurobiology with behaviour. Trends Cognitive Science, 11: 118-125.

Brandt, J. and Butters, N. (1986). The neuropsychology of Huntingtons disease. Trends in Neuroscience, 9: $118-120$.

Brown, R. G. and Marsden, C. D. (1990). Cognitive function in Parkinsońs disease: From description to theory. Trends in Neuroscience, 13: 21-29.

Brown, R. M. and Goldman, P. S. (1977). Catecholamines in neocortex of Rhesus monkey: Regional distribution and ontogenetic development. Brain Research, 124, 576-580.

Bruck, A., Aalto, S., Nurmi, E., Bergman, H. Rinne, J. O. (2005). Cortical 6-\%F18\&fluoro-L-dopa uptake and frontal cognitive functions in early Parkinson's disease. Neurobiology of Aging, 26: 891-898.

Bush, G., Shin, L. M., Holmes, J., Rosen, B. R., and Vogt, B. A. (2003). The Multi-Source Interference Task: Validation study with fMRI in individual subjects. Molecular Psychiatry, 8: 60-70.

Cabeza, R., Nyberg, L., and Park, D. (2005). Cognitive Neuroscience of Aging. New York: Oxford University Press.

Cai, J. X. and Arnsten, A. F. (1997). Dose-dependent effects of the dopamine receptor agonists A77636 and SKF81297 on spatial working memory in aged monkeys. Journal of Pharmacology and Experimental Therapeutics, 283: $183-189$.

Carlsson, A. (1975). Drugs acting through dopamine release. Pharmacological Therapy, 1; 401-405.

Castner, S. A. and Williams, G. (2007). Tuning the engine of cognition: A focus on NMDAD1 receptor interactions in prefrontal cortex. Brain and Cognition, 63: 94-122.

Cervenka, S., Bäckman, L., Cselényi, Z., Halldin, C., and Farde, L. (2008). Associations between dopamine $\mathrm{D}_{2}$-recptor binding and cognitive performance indicate functional compartmentalization of the human striatum. Neurolmage, 40: 1287-1295.

Chen, J., Myerson, J., and Hale, S. (2002). Age-related dedifferentiation of visuospatial abilities. Neuropsychologia, 40: 2050-2056.

Chen, M. K., Kuwabara, H., Zhou, Y., Adams, R. I., Brasic, I. R. McGlothan, J. L. et al. (2008). VMAT 2 and dopamine neuron loss in a primate model of Parkinson's disease. Journal of Neurochemistry, 105: 78-90.

Cohen, J. D. and Servan-Schreiber, D. (1992). Context, cortex, and dopamine A connectionist approach to behavior and biology in schizophrenia. Psychological Review, 99: 45-77.

Cools, R., Braker, R. A., Sahakian, B. J., and Robbins, T. W. (2001). Enhanced or impaired cognitive function in Parkinson's disease as a function of dopa. minergic medication and task demands. Cerebral Cortex, 11: 1136-1143.

Cools, R., Gibbs, S. E., Miyakawa, A., Jagust, W., and D'Esposito, M. (2008). Working memory capacity predicts dopamine synthesis capacity in the human striatum. Journal of Neuroscien $\alpha, 28: 1208-1212$

Cornish, K. M., Manly, T., Savage, R, Swanson, J., Morisano, D., Butler, N., Grant, C., Cross, G., Bentley, L., and Hollis, C. P. (2005). Association of the dopamine transporter (DAT1) 10/10-repeat genotype with ADHD symptoms and response inhibition in a general population sample Molecular Psychiatry, 10: 686-698.

Craik, F. I. M. and Salthouse, T. (2007). The Handbook of Aging and Cognition. New York: Psychological Press. 
Cropley, V. L., Fujita, M., Innis, R. B., and Nathan, P. J. (2006). Molecular imaging of the dopaminergic system and its association with human cognitive function. Biological Psychiatry 59: 898-907.

Dahlin, E., Neely Stigsdotter, A., Larsson, A., Bäckman, L., and Nyberg, L. (2008). Transfer of learning after updating training mediated by the striatum. Science, 320: 1510-1512.

D'Ardenne, K., McClure, S. M., Nystrom, L. E, and Cohen, J. D. (2008). Bold responses reflecting dopaminergic signals in the human ventral tegmental area. Saience, 318: 1264-1267.

Deary, I. J., Wright, A. F., Harris, S. E. Whalley, L. J., and Starr, J. M. (2004). Searching for genetic influences on normal cognitive aging. Trends in Cognitive Sciences, 8: 178-184.

de Frias, C. M., Annerbrink, K., Westberg, L., Eriksson, E., Adolfsson, R, and Nilsson L.-G. (2004). COMT gene polymorphism is associated with declarative memory in adulthood and old age. Behavior Genetics, 34: $533-539$.

de Frias, C. M., Annerbrink, K., Westberg, L., Eriksson, E., Adolfsson, R. Nilsson, L.-G. (2005). Catechol O-methyltransferase Val ${ }^{15 \%} \mathrm{Met}$ polymorphism is associated with cognitive performance in nondemented adults. Journal of Cognitive Neuroscience, 17: 1018-1025.

de Frias, C. M., Lövdén, M., Lindenberger, U., and Nilsson, L.-G. (2007) Revisiting the dedifefrentiation hypothesis with longitudinal multi-cohor data. Intelligence, 35: 381-392.

de Frias, C. M., Marklund, P., Eriksson, E., Larsson, A., Öman, L., Annerbrink, L. et al. (2008). Influence of COMT Gene Polymorphism on fMRI-Assessed Sustained and Transient Activity during a Working Memory Task. Manuscript submitted for publication.

De Keyser, J., De Backer, J. P., Vauquelin, G., and Ebinger, G. (1990). The effect of aging on the D1 dopamine receptors in human frontal cortex. Brain Research, 528, 308-310.

Durstewitz, D., Seamans, I. K., and Sejnowksi, T. J. (2000). Dopamine-mediated stablization of delay-period activity in network model of prefrontal cortex. Journal of Neurophysiology, 93: 1733-1750.

Eberling, J. L., Pivirotto, P., Bringas, J., and Bankiewic., K. S. (2004) Comparison of two methods for the analysis of [ $28 \mathrm{~F}]-6$-fluoro-L- $m$-tyrosine PET dopamineta. NeuroImage, 23: 358-363.

Egan, M. F., Goldberg, T. E., Kolachana, B. S., Callicott, J. H., Mazzanti, C. M. Straub, R. E. et al. (2001). Effect of COMT Val108/158Met genotype on frontal lobe function and risk for schizophrenia. Proceedings of the National Academy of Sciences of the USA, 98: 6917-6922

Erixon-Lindroth, N., Farde, L., Robins Wahlin, T. B., Sovago, J., Halldin, C. and Bäckman, L. (2005). The role of the striatal dopamine transporter in cognitive aging. Psychiatry Research: Neuroimaging, 138: 1-12.

Farde, L., Ginovart, N., Halldin, C., Chou, Y., Olsson, H., and Swahn, C. (2000). A PET-study of $[\mathrm{nC}] \mathrm{b}-\mathrm{CrT}$-FE binding to the dopamine transporter in the moneky and human brain. International Journal of Clinical Neuropsychopharmacology, 3: 203-214.

Farde, L., Hall, H., Fhrin, E., and Sedvall, G. (1986). Quantitative analysis of $\mathrm{D}_{2}$ dopamine receptor binding in the living human brain by PET. Science, 231: 258-261.

Farde, L., Halldin, C., Stone-Elander, S., and Sedvall, G. (1987). PET analysis of human dopamine receptor subtypes using $11 \mathrm{C}-\mathrm{SCH} 23390$ and uC-raclopride. Psychopharmacology, 92: 278-284

Farde, L., Suhara, T., Nyberg, S., Kartsson, P., Nakashima, Y., Hietala, J. et al. (1997). A PET-study of [11C]FLB 457 binding to extrastriatal D2-dopamine receptors in healthy subjects and antipsychotic drug treated patients. Psychopharmacology, 133: 396-404.

Fearnley, J. M. and Lees, A. J. (1991). Aging and Parkinsons disease: Substantia nigra regional selectivity. Brain, 114: 2283-230L.

Fischer, H., Nyberg, L., Karlsson, P., Farde, L., Karlsson, S., MacDonald, S. W. S. et al. (2008). Simulating Cognitive Aging: Effects of a Dopaminergic Antagonist on Brain Activation Patterns in Young Adults. Manuscript submitted.

Foley, T. E. and Fleshner, M. (2008). Neuroplasticity of dopamine circuits after exercise: Implications for central fatigue. Neuromolecular Medicine, 10: $67-80$.

Frankle, W. G. (2007). Neuroreceptor imaging studies in schizophrenia. Harvard Review of Psychiatry, 15: 213-232.
Frey, K. A., Vander Borght, T. M., Killbourn, J. N., DaSilva, J. E., Carey, J. E., and Kuhl, D. E. (1995). In vivo imaging of the brain vesicular monoamine transporter. Journal Nuclear Medicine, 36: 2252-2260

Garnett, E. S., Firnau, G., and Nahmias, C. (1983). Dopamine visualized in the basal ganglia of living man. Nature, 305: 137-138.

Gaspar, P., Berger, B., Febvret, A., Vigny, A., and Henry, J. P. (1989). Catecholamine innervation of the human cerebral cortex as revealed by comparative immunohistochemistry of tyroxine-hydroxylase and dopamine-beta-hydroxylase. Journal of Companative Neurology, 279: 249-271.

Girault. J. A. and Greengard, P. (2004). The neurobiology of dopamine signaling. Archives of Neurology, 61: 641-644.

Giros, B., El Mestikawy, S., Godinot, N., Zheng, K. Q., Han, H., Yangfeng. T. et al. (1992). Cloning, pharmacological characterization, and chromosome assignment of the human dopamine transporter. Moleailar Pharmacology, 3: 383-390.

Giros, B., Jaber, M., Jones, S. R., Wightman, R. M., and Caron, M. G. (1996). $\mathrm{Hyperlocomotion}$ and indifference to cocaine and amphetamine in mice lacking the dopamine transporter. Nature, 379: 606-612.

Goldberg, T. E. and Weinberger, D. R. (2004). Genes and the parsing of cognitive processes. Trends in Cognitive Sciences, 8: 325-335.

Goldman-Rakic, P. S., Muly, E. C., and Williams, G. V. (2000). D1 receptors in prefrontal cells and circuits. Brain Research Review, 31: 295-301.

Gopnic, A., Meltzoff, A., and Kuhl, P. (1999). The Scientist in the Crib: What Early Learning Tells Us About the Mind. New York: HarperCollins.

Grace, A. A., Floresco, S. B., Goto, Y., and Lodge, D. J. (2007). Regulation of firing of dopaminergic neurons and control of gioal-directed behaviors. Trends in Neurosciences, 30: 220-227.

Grady, C. L. (2002). Age-related differences in face processing: A metaanalysis of three functional neuroimaging experiments. Canadian Journal of Experimental Psychology, 56: 208-220.

Green, A. E., Munafo, M. R., DeYoung, C. G. (2008). Using genetic data in cognitive neuroscience: from growing pains to genuine insights. Nature Reviews Neuroscience, 9: 710-720.

Hall, H., Sedvall, G., Magnusson, O., Kopp, J., Halldin, C., and Farde, L. (1994). Distribution of $\mathrm{D}_{1}$ - and $\mathrm{D}_{2}$-dopamine receptors and dopamine and its metabolites in the human brain. Neuropsychopharmacology, u1: 245-256.

Halldin, C., Erixon-Lindroth, N., Pauli, S., Chou, Y. H., Okubo, Y. Karlsson, P. et al. (2003). [nC]PE.2I: A highly selective radioligand for PET examination of the dopamine transporter in monkey and human brain. European Journal of Nuclear Medicine, 30: 1220-1230.

Halldin, C., Foged, C., Karlsson, P, Swahn, C.-G., Sedvall, G., and Farde, L. (1998), [nC]NNC ux A radioligand for PET examination of striatal and extrastriatal D1-dopamine receptors. Journal of Nuclear Medicine, 39: 2061-2068.

Halld in, C., Gulyas, B., Langer, O., and Farde, L. (2001). Brain radioligands State of the art and new trends. Quarterly Journal of Nuclear Medicine, 45: 139-152.

Halliday, R., Naylor, H., Brandeis, D., Callaway, E., Yano, L., and Herzig. $K$. (1994). The effect of d-amphetamine, clonidine, and yohimbine on human information processing. Psychophysiology, 31: 331-337.

Hariri, A. R. and Wein berger, D. R. (2003). Imaging genomics. British Medical Bullet in, 65: 259-270.

Harris, S. E., Wright, A. F., Hayward, C., Starr, J. M., Whalley, L. J., and Deary, I. J. (2005). The functional COMT polymorphism, Vahs8Met, is associated with logical memory and the personality trait intellect/ imagination in a cohort of healthy 79 year olds. Neuroscience Letters, 385: $1-6$.

Heekeren, H. R., Marrett, S., and Ungerleider, L. G. (2008) The neural systems that mediate human perceptual decision making. Nature Reviews Neuroscience, 9: 467-479.

Heinz, A., Siessmeier, T., Wrase, J., Hermann, D., Grusser, S. M. Flor, H. et al. (2004). Correlation between dopamine D-2 receptors in the ventral striatum and central processing of alcohol cues and craving. American Journal of Psychiatry, 161: 1783-1789.

Hill, R. D., Bäckman, L., and Stigsdotter-Neely, A. (eds). (2000). Cognitive Rehabilitation in Old Age. New York: Oxford University Press

Inoue, M., Suhara, T., Sudo, Y., Okubo, Y., Yasuno, F., Kishimoto, T. et al. (2001). Age-related reduction of extrastriatal dopamine $D_{2}$ receptor measured by PET. Life Sciences, 69: 1079-1084. 
Ito, H., Takahashi, H., Arakawa, R., Takano, H., and Suhara, T. (2008). Normal database of dopaminergic neurotransmission system in human brain measured by positron emission tomography. Neurolmage, 39: 555-565.

Jaber, M., Jones, S., Giros, B., and Caron, M. G. (1997). The dopamine transporter: A crucial component regulating dopamine transmission. Movement Disorders, 12, 629-633.

Jones, S. R., Gainetdinov, R. R., Jaber, M., Giros, B., Wightman, R. M., and Caron, M. G. (1998). Profound neural plasticity in response to inactivation of the dopamine transporter. Proceedings of the National Academy of Sciences of the USA, 95: 4029-4034.

Kaasinen, V. and Rinne, J. O. (2002). Functional imaging studies of dopamine system and cognition in normal aging and Parkinson's disease. Neuroscience and Biobehaviomal Reviews, 26: 785-793.

Kaasinen, V., Vilkman, H., Hietala, J., Nagren, K., Helenius, H. Olsson, H. et al. (2000). Age-related $\mathrm{D}_{2} / \mathrm{D}_{3}$ receptor loss in extrastriatal regions of the human brain. Neurobiology of Aging, 21: 683-688.

Kartsson, S., Nyberg. L., Karlsson, P., Farde, L., Fischer, H., MacDonald, S. W. S. et al. (2008). Age-related differences in reduction of dopamine $D_{1}$ receptor binding measured with (11 Cl SCH 23390 during cognitive activity compared to resting state. Manuscript submitted.

Kessler, R. M., Whetsell, W. O., Ansari, M. S. et al. (1993). Identification of extrastriatal dopamine D2 receptors in post mortem human brain with 125I ]epidepride. Brain Research, 609: 237-243.

Kimberg, D. Y. and D'Esposito, M. (2003). Cognitive effects of the dopamine receptor agonist pergolide. Neuropsychologia, 41: 1020-1027.

Kimberg, D. Y., D'Esposito, M., and Farah, M. J. (1997). Effects of bromocriptine on human subjects depend on working memory capacity. NeuroReport, 8: 3581-3585.

Koepp, M. J., Gunn, R. N., Lawrence, A. D., Cunningham, V. J., Dagher, A., Jones, T. et al. (1998). Evidence for striatal dopamine release during a video game. Nature, 393: 266-268.

Kohler, C., Ericson, H. and Radesater, A. C. (1991). Different laminar distributions of dopamine $\mathrm{D}_{1}$ and $\mathrm{D}_{2}$ receptors in the rat hippocampal region. Neuroscience Letters, 126: 107-109.

Knutson, B. and Gibbs, S. E. B. (2007). Linking nucleus accumbens dopamine and blood oxygenation. Psychopharmacology, 191: $813-822$

Lacor, P. N. (2007). Advances on the understanding of synaptic pathology in AD. Current Genomics, 8: 486-508.

Larkin, G. R. S., Gibs, S. E. B., Khanna, K., Nielsen, L., Castensen, L., and Knuston, B. (2007). Anticipation of mentary gain but not loss in healthy older adults. Nature Neuroscien $\alpha$, 10: 787-791.

Laruelle, M. (2000). Imaging synaptic neurotransmission with in vivo binding competition techniques: A critical review. Journal of Cerebral Blood Flow and Metabolism, 20: 423-451

Laurier, L. G., O'Dowd, B. F., and George, S. R. (1994). Heterogeneous tissue-specific transcription of dopamine receptor subtype messenger RNA in rat brain. Brain Research and Molecular Brain Research, 25: 344-350.

Lawrence, A. D., Weeks, R. A., Brooks, D. J., Andrews, T. C., Watkins, L. H. A., Harding, A. E. et al. (1998). The relationship between dopamine receptor binding and cognitive performance in Huntington's disease. Brain, 121: 1343-1355.

Lewis, D. A. and Sesack, S. R. (1997). Dopamine systems in the primate brain. In E. F. Bloom, A. Björllund, and T. Hölfelt (eds), The Primate Nervous System Part 1 (pp. 263-375). Amsterdopaminem: Elsevier.

Li, S.-C., Biele, G., Mohr, P. N. C, and Heekeren, H. (2007). Aging and neuroeconomics: Insights from research on neuromodulation of reward-based decision making. Analyse and Kritik, 29: 97-11.

Li, S.-C., Lindenberger, U., and Sikström, S. (2001). Aging cognition: From neuromodulation to representation to cognition. Trends in Cognitive Sciences, 5: 479-486

Li, S.-C., Lindenberger, U., Hommel, B., Aschersleben, G., Prinz, W., and Baltes, P. B. (2004). Transformations in the couplings among intellectual abilities and constituent cognitive processes across the lifespan. Psychological Science, 15: 155-163.

Li, S.-C. and Sikström, S. (2002). Integrative neurocomputational perspectives on cognitive aging, neuromodulation, and representation. Neuroscience and Biobehavional Reviews, 26: 795-808.
Li, S.-C., von Oertzen, T., and Lindenberger, U. (2006). A neurocomputational model of stochastic resonance and aging. Neurocomputing, 69: $1553-1560$.

Lindenberger, U. and Baltes, P. B. (1994). Sensory functioning and intelligence in old age: A strong relation. Psychology and Aging, 9: 339-355.

Lindenberger, U., Li, S.-C., and Bäckman, L. (2006). (eds). Special issue: Brain-behavior dynamics across the lifespan. Neursocience and Biobehavioral Reviews, 30: 713-885.

Lindenberger, U., Nagel, I. E., Chicherio, C., Li, S.-C., Heekeren, H., and Bäckman, L. (2008). Age-related decline in brain resources modulates genetic effects on cognitive functioning. Frontier in Neurosciena, 2 , 234-244.

Loo, S. K., Specter, E., Smolen, A., Hopper, C., Teale, P. D., and Reite, M. L. (2003). Functional effects of the DAT1 polymorphism on EEG measures in ADHD. Journal of the American Academy of Child and Adolescent Psychiatry, 42: 986-993.

Lotta, T., Vidgren, J., Tilgmann, C., Ulmanen, I., Julkunen, I., and Taskinen, J. (1995). Kinetics of human soluble and membrane-bound catechol-O-methyltransferase: $\mathrm{A}$ revised mechanism and description of the termolabile variant of the enzyme. Biochemistry, 34: 4202-4210.

Lövdèn, M., Li, S.-C., Shing, Y. L., and Lindenbeger, U. (2007). Within-person trial-to-trial variability precedes and predicts cognitive dedine in old and very old age: Longitudinal data from the Berlin Aging Study. Neuropsychologia, 45: $2827-2838$.

Luciana, M. and Collins, P. F. (1997). Dopamine modulates working memory for spatial but not object cues in normal humans. Joumal of Cognitive Neuroscience, 9: 330-347

MacDonald, S. W. S., Cervenka, S., Farde, L., Nyberg, L., and Bäckman, L. (in press). Extrastriatal Dopamine $\mathrm{D}_{2}$ receptor binding modulates intraindividual variability in episodic memory and executive functioning. Neuropsychologia.

MacDonald, S. W. S., Nyberg, L., and Bäckman, L. (2006). Intra-individual variability in behavior: Links to brain structure, neurotransmission, and neuronal activity. Trends in Neurosciences, 29: 474-480.

MacRae, P. G., Spirduso, W. W., and Wilcox, R. E. (1988). Reaction time and nigrostriatal dopamine function: The effects of age and practice. Brain Research, 451: 139-146.

Maher, B. S., Marazita, M. L., Ferrell, R. E., and Vanyukov, M. M. (2002). Dopamine system genes and attention deficit hyperactivity disorder: A meta-analysis. Psychiatric Genetics, 12: 207-215.

McGuire, P., Howes, O. D., Stone, J., and Fusar-Poli, P. (2008). Functional neuroimaging in schizophrenia: Diagnosis and drug discovery. Trends in Pharmacologiaal Sciences, 29: 91-98.

Marschner, A., Mell, T., Wartenburger, I., Villringer, A., Reischies, F. M., and Heekeren, H. R. (2005). Reward-based decision making and aging. Bmain Research Bulletin, 67: 382-390.

Mattay, V. S., Goldberg, T. E., Fera, F., Hariri, A. R., Tessitore, A., and Egan, M. F. (2003). Catechol-O-methyltransferase val(258)-met genotype and individual variation in he brain responses to amphe tamine. Proceedings of the National Academy of Sciences of the USA. 100: 6186-6191.

Mattay, V. S., Goldberg, T. E., Sambataro, F., and Weinberger, D. R. (2008). Neurobiology of cognitive aging: Insights from imaging genetics Biological Psychology, 79: 9-22

Meador-Woodruff, J. H. (1994). Update on dopamine receptors. Annals of Clinical Psychiatry, 6: 79-90.

Mell, T., Heekeren, H. R., Marschner, A., Wartenburgerm, I., Villringer, A. and Reischies, F.M. (2005). Effect of aging on stimulus-related association learning. Neuropsychologia, 43: 554-563.

Mesco, E. R., Carlsson, S. G., Joseph, I. A., and Roth, G. S. (1993). Decreased striatal $\mathrm{D}_{2}$ dopamine receptor mRNA synthesis during aging. Molecular Brain Research, 17: 160-162.

Meyer-Lindenberg, A. and Weinberger, D. R. (2006). Intermediate phenotypes and genetic mechanisms of psychiatric disorders. Nature Reviews Neuroscience, 7: 818-827.

Mever-Lindenberg, A., Straub, R. E., Lipska, B. K., Verchinski, B. A. Goldberg, T., and Callicott, I. H. et al. (2007). Genetic evidence 
implicating DARPP-32 in human frontostriatal structure, function, and cognition. Journal of Clinical Investigations, 117: 672-682.

Martinez, D., Silfstein, M., Broft, A., Mawlawi, O., Hwang, D.-R. Huang, Y. et al. (2003). Imaging human mesolimbic dopamin transmission with positron emission tomography. Part II Amphetamine-induced dopamine release in the functional subdivisions of the striatum. Journal of Cerebral Blood Flow and Metabolism. 23: 285-300.

Mitchell, R. J., Howlett, S., Earl, L., McComb, J., Schanfield, M. S., Briceno, I et al. (2000). Distribution of the VNTR polvmorphism in the human dopamine transporter gene in world populations. Human Biology, 72 295-304

Monchi, O., Ko, J. H., and Strafella, A. P. (2006). Striatal dopamine release during performance of executive functions: $\mathrm{A}[\mathrm{nC}]$ raclopride PET study. Neuroimage, 33: 907-912.

Montague, P. R., Hyman, S. E., and Cohen, J. D. (2004). Computational moles for dopamine in behavioural control. Nature, 431: 760-767.

Morgan, D. G. and May, P. C (1990). Age-related changes in synaptic neurochemistry. In Schneider and Row (eds), Handbook of the Biology of Aging (pp. 219-250). New York Academic Press.

Mozley, L. H., Gur, R. C., Mozley, P. D., and Gur, R. E. (2001). Striatal dopamine transporters and cognitive functioning in healthy men and women. American Joumal of Psychiatry, 158: 1492-1499.

Murtha, S., Cismaru, R., Waechter, R, and Chertkow, H. (2002). Increased variability accompanies frontal lobe damage in dementia. Joumal of the International Neuropsychological Society, 8: 360-372.

Nagel, I. E., Chicherio, C., Li, S.-C., von Oertzen, T., Sander, T. Villringer, A. et al. (2008). Human aging magnifies genetic effects on executive functioning and working memory. Frontiers in Human Neuroscience, $2: 1-8$

Nahmias, C., Wahl, L. et al. (1995). A probe for intracerebral aromatic amino-acid decarboyxlase activity: distribution and kinetics of [18F]6-fluoro-L- $m$-tyrosine in the human brain. Movement Disonder, 10 298-304

Neumever, J. L., Wang, S., Milius, R. A., Baldwin, R. M., Zeaponce, Y., Hoffer, P. B. et al. (1991). [ $\left.{ }^{123} \mathrm{I}\right]-2$-b -carbomethoxy-3b-(4-iodophenyl)-tropane High-affinity SPECT radiotracer of monoamine reuptake sites in brain Journal of Medicinal Chemistry, 34: 3144-3146

Nordström, A. L., Farde, L., Pauli, S., Litton, J. E., and Halldin, C. (1992). PET analysis of $[\mathrm{nC}]$ raclopride binding in healthy young adults and schizi phrenic patients: Reliability and age effects. Human Psychopharmacology. 7:157-165.

Nyberg, L., Sandblom, J., Jones, S., Stigsdotter-Neely, A., Petersson, K. M., Ingvar, M., and Bäckman, L. (2003). Neural correlates of training-related memory improvement in adulthood and aging. Proceedings of the National Academy of Sciences of the USA, 100: 13728-13733.

Nyberg, L., Andersson, M., Forsgren, L., Jakobsson-Mo, S., Larsson, A. Marklund, P. et al. (2008). Striatal dopamine $\mathrm{D}_{2}$ binding is related to frontal BOLD response during updating of long-term memory representations. Manuscript submitted.

O'Hara, R., Miller, E., Liao, C. P., Way, N., Lin, X. Y., and Hallmaver, J. (2006). COMT genotype, gender, and cognition in community dwelling, older adults. Neuroscience Letters, 409: 205-209.

O'Reilly, R. C. (2006). Biological based computational models of high-leve cognition. Science, 314: 91-94.

O'Reilly, R. C. and Frank, M. J. (2006). Making working memory work a computational model of leaming in the frontal cortex and basal ganglia. Neural Computation, 18: 283-328.

Parent, A. and Hazrati, L. N. (1995). Functional anatomy of the basal ganglia. I. The cortico-basal ganglia-thalamo-cortical loop. Brain Research Review, 20: 91-127.

Pasuit, J. B., Li, Z., and Kuzhikandathil, V. (2004). Joumal of Neurochemistry, 89: 1508-1519.

Pizzagalli, D. A., Evins, A. E., Schetter, E. C., Frank, M. J., Paitas, P. E. Santesso, D. L., and Culhane, M. (2008). Single dose of a dopamine agonist impairs reinforement learning in humans: Behavioral evidence from a laboratory-based measure of reward responsiveness. Psychopharmacology, 196: 221-232.
Ramaekers, J. G., Louwerens, J. W., Muntjewerff, N. D., Milius, H., de Bie, A. Rosenzweig, P. et al. (1999). Psychomotor, cognitive, extrapyramidopa $m$ inel and affective functions of heal thy volunteers during treatment with an atypical (amisulpiride) and a classic (haloperidol) antipsychotic. Journal of Clinical Psychopharmacology, 19: 209-221.

Raz, N. Williamson, A. Gunning-Dixon, F. Head, D, and Acker, J. D. (2000). Neuroanatomical and cognitive correlates of adult age differences in acquisition of a perceptual-motor skill. Miroscopy Research and Technique, a Special Issue on Neuroimaging and Memory, 51: 85-93.

Rieck, R. W., Ansari, M. S., Whetsell, Jr., W. O., Deutch, A. Y., Kessler, R. M. (2004). Distribution of dopamine D2-like receptors in the human thalamus: autoradiographic and PET studies. Neuropsychopharmacology, 29: $362-372$

Rolls, E. T., Loh, M., Deco, G., and Winterer, G. (2008). Computational models of schizophrenia and dopamine modulation in the prefrontal cortex. Nature Reviews Neuroscience, 9: 696-709.

Roth, R. H. (1984). CNS dopamine autorecepton: Distribution, pharmacology and function. Annals of the New York Academy of Sciences, 430: 27-53.

Sánchez-González, M. A., Garcia-Cabezas, M. A., Rico, B., and Cavada, C. (2005). The primate thalamus is a key target for brain dopamine. Journal of Neuroscience, 25: 6076-6083.

Sawaguchi, T. and Goldman-Rakic, P. S. (1991). D 1 dopamine receptors in prefrontal cortex: Involvement in working memory. Science, 251: $947-950$

Sawamoto, N., Piccini, P., Hotton, G., Pavese, N., Thielemans, K., and Brooks. D. J. (2008). Cognitive deficits and striato-frontal dopamine release in Parkinson's disease. Brain, 131: 1294-1302.

Schambra, U. B., Duncan, G. E., Breese, G. R., Fornaretto, M. G., Caron, M. G., and Fremeau, J. R. (1994). Ontogeny of D1a and D2 dopamine receptor subtypes in rat brain using in situ hybridization and receptor binding. Neuroscience, 62: 65-85.

Schott, B. H., Minuzzi, L., Krebs, R. M., Elmenhorst, D., Lang, M., Winz. O. H. et al. (2008). Mesolimbic fMRI activations during reward anticipation correlate with reward-related ventral striatal dopamine release. Journal of Neuroscience, 28: 14311-14319.

Schultz, W., Studer, A, Romo, R., Sundstrom, E., Jonsson, G., and Scarnati, E. (1989). Deficits in reaction-times and movement times as correlates of hypokinesia in monkeys with MPTP-induced striatal dopamine depletion. Journal of Neurophysiolosy, 61, 651-668.

Schultz, W. (2006). Behavioral theories and the neurophysiology of reward. Annual Review of Psychology, 57: 87-115.

Seamans, J. K. and Yang, C. R. (2004). The principal features and mechanisms of dopamine modulation in the prefrontal cortex. Progress in Neurobiology, 74: 1-57.

Seeman, P., Bzowej, N. H., Guan, H. C., Bergeron, C., Becker, L. E., Reynolds, G. P. et al. (1987). Human brain dopamine receptors in children and aging adults. Synapse, 1: 399-404.

Segovia, G., Porras, A., Arco, A. D., and Mora, F. (2001). Glutamatergic neurotransmission in aging: A critical perspective. Mechanisms of Ageing and Development, 122: 1-29.

Servan-Schreiber, D., Printz, H., and Cohen, J. D. (1990). A network model of catecholamine effects: Gain, signal-to-noise ratio, and behavior. Science, 249: 892-895.

Servan-Schreiber, D., Carter, C. S., Bruno, R. M., and Cohen, J. D. (1998). Dopamine and the mechanisms of cognition: Part II. D-amphetamine effects in human subjects performing a selective attention task. Biological Psychiatry, 43: 723-729.

Severson, J. A., Marcusson, J., Winblad, B., and Finch, C. E. (1982). Age-correlated loss of dopaminergic binding sites in human basal ganglia. Journal of Neurochemistry, 39: 1623-1631.

Shinkai, T., Zhang, L., Mathias, S. A., and Roth, G. S. (1997). Dopamine induces apoptosis in cultured rat striatal neurons: Possible mechanism of $\mathrm{D}_{2}$-dopamine receptor neuron loss during aging. Joumal of Neuroscience Research, 47: 393-399.

Snow, B. J., Tooyama, I., McGeer, E. G., Yamada, T., Calne, D. B., Takahashi, H. et al. (1993). Human positron emission tomographic [18F] fluorodopa studies correlate with dopamine cell counts and levels. Annals of Neurology, 34: 324-330. 
Starr, J.M., Fox, H., Harris, S. E., Deary, I. J., and Whalley, L. J. (2007). COMT genotype and cognitive ability: A longitudinal aging study. Neuroscience Letters, 421: $57-61$.

Stefanis, N. C., van Os, J., Avramopoulos, D., Smyrnis, N., Evdokimidis, I. and Stefanis, C. N. (2005). Effect of COMT Val(158)Met polymorphism on the continuous performance test, identical pairs version: Tuning rather improving performance. American Journal of Psychiatry, 162: 1753-1754.

Stoessl, A. J. and de la Fuente-Femandez, R. (2003). Dopamine receptors in Parkinson's disease: imaging studies. Advanced Neurology, 91: 65-71.

Stuss, D. T., Murphy, K. I., Binns, M. A on the job: The frontal lobes control individual performance variability. Brain, 126: 2363-2380.

Suhara, T., Fukudopamine, H., Inoue, O., Itoh, T., Suzuki, K., Yamasaki, T. Tateno, Y. (1991). Age-related changes in human $\mathrm{D}_{1}$ dopamine receptors measured by positron emission tomography. Psychopharmacology, 103: 41-45.

Takah ashi. H., Kato, M., Hayashi, M., Okubo, Y., Takano, A., Ito, H. et al. (2006). Memory and frontal lobe functions: Possible relations with dopamine $D_{2}$ receptors in the hippocampus. Neurolmage, 34: 1643-1649.

Tan, H. Y., Chen, Q, Sust, S., Buckholtz, W. Mevers, J. D., Egan, M. F. et al. (2007). Epistasis between catechol-O-Methyltransferase and type II metabotropic glutamate receptor 3 genes on working brain function. Proceedings of the National Academy of Sciences of the USA, 104: 12536-12541.

Taylor, S. F., Koeppe, R. A., Tandon, R., Zubieta, J. K., and Frey, K. A. (2000) In vivo measurement of the vesicular monoamine transporter in schizophrenia. Neuropsychopharmacology, 6: 667-675.

Ungerstedt, U. (1971). On the Anatomy, Pharmacology, and Function of the Nigrostriatal Dopamine System. Stockholm: Norstedts.

Volkow, N. D., Gur, R. C., Wang, G. J., Fowler, J. S., Moberg, P. J., Ding, Y. S. et al. (1998). Association between decline in brain dopamine activity with age and cognitive and motor impairment in healthy individuals. American Journal of Psychiatry, 157: 344-349.

Wang, M., Vijayraghavan, S., and Goldman-Rakic, P. S. (2004). Selective D2 receptor actions on the functional circuity of working memory. Science, 303: 853-856.

Wang, Y., Chan, G. L. Y., Holden, J. E., Dobko, T., Schulzer, M. E., Huser, J. M. et al. (1998). Age-dependent decline of dopamine D1 receptors in human brain: A PET study. Synapse, 30: 56-61.
Weinshilboum, R. M., Otterness, D. M., and Szumlanski, C. L. (1999). Methylation pharmacogenetics: Catechol-O-methyltransferase, thiopurine methyltransferase, and histamine $\mathrm{N}$-methyltransferase. Annual Review of Pharmacology and Toxicology, 39: 19-52.

West, R., Murphy, K. J., Armilio, M. L., Craik, F. I. M., and Stuss, D. T. (2002). Lapses of intention and performance variability reveal age-related increases in fluctuations of executive control. Brain and Cognition, 49: 402-419.

Winterer, G., Coppola, R., Goldberg, T. E., Egan, M. F., Jones, D. W., Sanchez, C. E., and Weinberger, D. R. (2004). Prefrontal broadband noise, working memory, and genetic risk for schizophrenia. America Journal of Psychiatry, 161: $490-500$.

Winterer, G. and Weinberger D. R. (2004) Genes, dopamine and cortical signal-to-noise ratio in schizophrenia. Trends in Neuroscience, 27. 683-690.

Winterer, G., Musso, F., Vucurevic, G., Stoeter, P., Konrad, A., Seker, B. 'et al. (2006). COMT genotype predicts BOLD signal and noise characteristics in prefrontal circuits. Neuroimage, 32: 1722-1732.

Williams, G. V. and Goldman-Rakic, P. S. (1995). Modulation of memory fields by dopamine D1 receptors in prefrontal cortex. Nature, 376: 572-575.

Wittmann, B. C., Schott, B. H., Guderian, S., Frey, J. U., Heinze, H. J., Duzel, E. (2005). Reward-related FMRI activation of dopaminergic midbrain is associated with enhanced hippocampus-dependent long-term memory formation. Neuron, 5: 459-467.

Yacubian, J., Sommer, T., Schroeder, K., Gläscher, J., Kalisch, R., Leuenberger, B. et al. (2007). Gene-gene interaction associated with neural reward sensitivity. Proceedings of the National Academy of Sciences of the USA, 104: 8125-8130

Yang, Y. K., Chiu, N. T., Chen, C. C, Chen, M., Yeh, T. L., and Lee, I. H. (2003). Correlation between fine motor activity and striatal dopamine $\mathrm{D}_{2}$ receptor density in patients with schizophrenia and healthy controls. Psychiatry Research: Neuroimaging, 123: 191-197.

Zhang, L., Ravipati, A., Joseph, J., and Roth, G. S. (1995). Aging-related changes in rat striatal $D_{2}$ dopamine receptor $m R N A$-containing neurons: A quantitative nonradioactive in situ hybridization study. Journal of Neuroscience, 15: 1735-1740. 